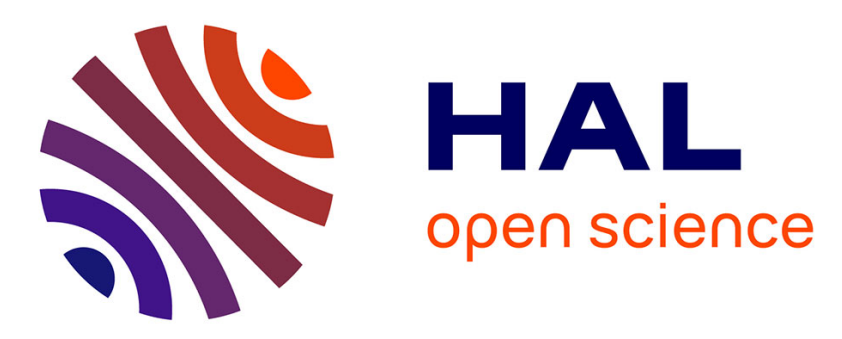

\title{
An in-situ electron microscopy study of dual ion-beam irradiated xenotime-type ErPO_4
}

\author{
Mohamed Ruwaid Rafiuddin, Anne-Magali Seydoux-Guillaume, Xavier \\ Deschanels, Adel Mesbah, Cedric Baumier, Stephanie Szenknect, Nicolas
}

Dacheux

\section{To cite this version:}

Mohamed Ruwaid Rafiuddin, Anne-Magali Seydoux-Guillaume, Xavier Deschanels, Adel Mesbah, Cedric Baumier, et al.. An in-situ electron microscopy study of dual ion-beam irradiated xenotimetype ErPO_4. Journal of Nuclear Materials, 2020, 539, pp.152265. 10.1016/j.jnucmat.2020.152265 . hal-02905196

\section{HAL Id: hal-02905196 https://hal.science/hal-02905196}

Submitted on 13 Nov 2020

HAL is a multi-disciplinary open access archive for the deposit and dissemination of scientific research documents, whether they are published or not. The documents may come from teaching and research institutions in France or abroad, or from public or private research centers.
L'archive ouverte pluridisciplinaire HAL, est destinée au dépôt et à la diffusion de documents scientifiques de niveau recherche, publiés ou non, émanant des établissements d'enseignement et de recherche français ou étrangers, des laboratoires publics ou privés. 


\section{An In-Situ Electron Microscopy Study of Dual Ion-Beam Irradiated Xenotime-type ErPO4}

Mohamed Ruwaid Rafiuddin,,${ }^{1, *}$ Anne-Magali Seydoux-Guillaume, ${ }^{2,3, *}$ Xavier Deschanels, ${ }^{1}$ Adel Mesbah, ${ }^{1}$ Cedric Baumier, ${ }^{4}$ Stephanie Szenknect, ${ }^{1}$ and Nicolas Dacheux ${ }^{1}$

${ }^{1}$ ICSM, Univ Montpellier, CEA, CNRS, ENSCM, Marcoule, France

${ }^{2}$ Univ Lyon, Univ Lyon 1, ENSL, CNRS, LGL-TPE, F-69622, Villeurbanne, France

${ }^{3}$ Univ Lyon, UJM-Saint-Etienne, CNRS, LMV UMR 6524, F-42023, Saint-Etienne, France

${ }^{4}$ CSNSM, JANNuS-Orsay/SCALP, University Paris-Sud, CNRS/IN2P3, Orsay, France

* Author to whom correspondence should be addressed

E-mail: Mohamed-Ruwaid.RAFIUDDIN@cea.fr ; anne.magali.seydoux@univ-st-etienne.fr 


\begin{abstract}
Rare-earth phosphates adopting the xenotime $\left(\mathrm{REPO}_{4} ; \mathrm{RE}=\mathrm{Tb}-\mathrm{Lu} \& \mathrm{Y}, \mathrm{Sc}\right)$ structure are proposed as a potential matrix for the confinement of minor actinides. Minor actinides (e.g., Np, $\mathrm{Am}, \mathrm{Cm})$ undergo a radioactive decay process in which high-energy recoil atom $(70-100 \mathrm{keV})$ and energetic alpha particles $(4.5-5.8 \mathrm{MeV})$ are produced. In this study, the impact of these energetic decay products on the structure of xenotime-type $\mathrm{ErPO}_{4}$ has been investigated via high energy dual ion-beam irradiation of $\mathrm{ErPO}_{4}$ ceramics. $\mathrm{Au}^{2+}(1.5 \mathrm{MeV})$ and $\mathrm{He}^{+}(160 \mathrm{keV})$ ions were used to simulate the effects of recoil atom and $\alpha$-particles, respectively. Multiple experiments were carried out in which the $\mathrm{Au}^{2+}$ and $\mathrm{He}^{+}$ions with varying ion-fluences (ions $/ \mathrm{cm}^{2}$ ) and ion-flux (ions $/ \mathrm{cm}^{2} / \mathrm{s}$ ) were implanted sequentially $\left(\mathrm{Au}^{2+}\right.$ followed by $\mathrm{He}^{+}$irradiation) and simultaneously $\left(\mathrm{Au}^{2+}+\mathrm{He}^{+}\right.$irradiation $)$into $\mathrm{ErPO}_{4}$ ceramics. Sequential ion-irradiation experiments have shown that the xenotime structure was amorphized by $\mathrm{Au}^{2+}$ ions at a relatively lower ion-fluence $\left(5 \times 10^{13}\right.$ ions $/ \mathrm{cm}^{2}$ ) in comparison to the monazite structure. Upon irradiation of the amorphous $\mathrm{ErPO}_{4}$ with $\mathrm{He}^{+}$ions, recrystallization of the amorphous xenotime due to $\alpha$-particles was not observed. However, simultaneous ion-irradiation experiments on $\mathrm{ErPO}_{4}$ showed that the amorphization of the xenotime structure was prevented upon deposition of higher amounts of electronic energy (Eelectronic) in the lamella. Likewise monazite samples, the $\alpha$-healing mechanism was also experimentally demonstrated in synthetic xenotime samples.
\end{abstract}




\section{Introduction}

Xenotime $\left(\mathrm{REPO}_{4} ; \mathrm{RE}=\mathrm{Tb}\right.$ to $\mathrm{Lu}$ and $\left.\mathrm{Y}, \mathrm{Sc}\right)$ is a commercially important rare-earth mineral and is usually found as accessory inclusions in igneous and metamorphic rocks.[1-8] Natural xenotime minerals are rich in yttrium and also contain variable amounts of heavy rare-earth elements (HREE).[1,9-11] Xenotime mineral crystallizes in the zircon structure type in the tetragonal crystal system with space group: I4 1 /amd (Figure 1).[7] In the structure, the REE atoms are coordinated to eight oxygen atoms and the resulting $\mathrm{REEO}_{8}$ dodecahedra are connected to the $\mathrm{PO}_{4}$ tetrahedra via corner sharing.[7] This mineral is also reported to contain variable amounts of tetravalent actinides such as uranium and thorium occupying the REE site.[1,12,13]

Xenotime minerals have been exposed to radiation events due to the $\alpha$-decay of ${ }^{238} \mathrm{U}$ and ${ }^{232}$ Th over geological timescales. During an $\alpha$-decay event, recoil atom $(70-100 \mathrm{keV})$ and $\alpha$ particles $(4.5-5.8 \mathrm{MeV})$ are produced. The energies of the recoil atoms and $\alpha$-particles are deposited in the mineral through ballistic and ionization process, respectively. Ballistic effects are primarily responsible for initiating the metamictization (i.e., crystalline to amorphous transformation) events commonly observed in natural minerals. Thus, assessing the impact of radiation on the mineral structure is necessary to adjudge whether synthetic analogues of xenotime mineral could be useful as a host-matrix for the immobilization of minor actinides (e.g., Np, Am, $\mathrm{Cm})$. Yet, to the best of our knowledge, very limited data is available on the radiation response of natural xenotime samples. Anderson et al. have studied the effects of radiation on natural xenotime specimens by analyzing ${ }^{238} \mathrm{U}$ and ${ }^{232} \mathrm{Th}$ containing xenotime minerals using Raman spectroscopy.[1] The $\alpha$-dose of the xenotime specimen was determined to be $1.59 \pm 0.03 \times 10^{16} \alpha$ decay/g.[1] The similarities of the Raman spectra of natural and synthetic xenotime samples implies the crystalline nature of the xenotime mineral.[1] Using Raman spectroscopy, Svecova et 
al. also investigated the effect of radiation damage on various natural xenotime samples.[14] In this study, the $\alpha$-doses of the analyzed xenotime specimens were higher by three orders of magnitude $\left(0.3-7.3 \times 10^{19} \alpha\right.$-decay/g) in comparison to those studied by Anderson et al.[1,14] Svecova et al. showed that the crystallinity of xenotime minerals was found to be either well or poorly crystalline depending on the $\mathrm{U}$ and Th contents.[14]

The results obtained from natural xenotime minerals are comparable with those obtained from natural monazite samples.[15-17] This is primarily because monazite and xenotime minerals, which belong to the same family of phosphate minerals, have the same general chemical formula and differ from one another in terms of crystal structure, size, and coordination number of RE ion.[12] It is worth noting here that natural monazite minerals were never found in a fully amorphous state and have remained crystalline at the geological timescale.[16,18] However, several investigations carried out on natural and synthetic analogues of monazite mineral showed that the monazite minerals were easy to amorphize but can be brought back to the initial crystalline state through dynamic healing of radiation-induced structural defects.[19-21] Healing of structural defects in monazite is possible via low temperature thermal annealing and/or energy deposition in the mineral due to $\alpha$-particles.[19,20] Such behaviour was not observed for the mineral zircon $\left(\mathrm{ZrSiO}_{4}\right)$, which is isostructural with the xenotime mineral.[22] Evidently, phosphate-based minerals (monazite and xenotime) are structurally more resilient than silicate (zircon) minerals and the structural resilience of phosphate minerals has been ascribed to their lower critical amorphization temperature $\left(\mathrm{T}_{\mathrm{c}}\right)$ and lower activation energy for recrystallization process.[2] Based on these mineralogical evidences, synthetic analogues of monazite and xenotime have been proposed as potential waste forms for the immobilization of minor actinides. 
Radiation effects on synthetic xenotime materials were determined using internal and external irradiation experiments. In internal irradiation, short-lived actinides (e.g., ${ }^{244} \mathrm{Cm}\left[\mathrm{T}_{1 / 2}=\right.$ 18.1 years]) were incorporated into the host matrix and the structural response was studied as a function of time.[23] Luo et al. examined the structure of $1 \mathrm{wt} \%{ }^{244} \mathrm{Cm}$-doped $\mathrm{LuPO}_{4}$ (xenotimetype) crystal using Transmission Electron Microscopy (TEM).[24] The radiation dose accumulated in the crystal due to the $\alpha$-decay of ${ }^{244} \mathrm{Cm}$ to ${ }^{240} \mathrm{Pu}$ was determined to be $5 \times 10^{19} \alpha$ decay/g.[24] It was shown that the crystallinity of the $\mathrm{LuPO}_{4}$ material remained largely unaffected by the $\alpha$-decay events of ${ }^{244} \mathrm{Cm}$ and it was proposed that the rates of damage production and recovery were similar.[24]

The long-term effects of radiation are simulated in a shorter timescale by employing the external irradiation method in which high energy ions (e.g., $\mathrm{Au}^{2+}, \mathrm{He}^{+}$) of varying ion fluences (ions $/ \mathrm{cm}^{2}$ ) are implanted in the solid. In an early study reported by Meldrum et al., crystals of synthetic xenotime were irradiated with heavy ions $\left(800 \mathrm{keV} \mathrm{Kr}^{2+}\right)$ and studied using TEM.[2] Meldrum et al. argued on the basis of critical amorphization temperature $\left(\mathrm{T}_{\mathfrak{c}}\right)$, that the xenotime materials were more susceptible to radiation damage than the monazite materials.[2] In another recent investigation on the structural stability of heavy ion-irradiated xenotime, evidence of a partial structural damage recovery was observed in $\mathrm{Au}^{-}(2 \mathrm{MeV})$ ion-irradiated $\mathrm{YbPO}_{4}$ (ion fluence $-1 \times 10^{15}$ ions $/ \mathrm{cm}^{2}$ ) materials using X-ray absorption near-edge spectroscopy (XANES).[25] Molecular dynamics simulation studies on $\mathrm{YPO}_{4}$ by Urusov et al. also reported the partial recovery of the damaged xenotime structure.[26] In that study, a $20 \mathrm{keV}^{232} \mathrm{Th}$ atom was used as the primary recoil atom for initiating a cascade of atomic displacements.[26] Post-irradiation, some of the partially displaced atoms return to their original atomic sites thereby initiating a partial structural recovery of the xenotime structure.[26] Lenz et al. in a recent study implanted xenotime-type 
$\left(\mathrm{YPO}_{4}\right)$ ceramics sequentially with $\mathrm{Au}^{-}$ions of different energies $(35,22,14,7 \mathrm{MeV})$ and fluences $\left(1.6 \times 10^{13}-6.5 \times 10^{13}\right.$ ions $\left./ \mathrm{cm}^{2}\right)$ and determined the amount of amorphous fraction using photoluminescence spectroscopy.[27] Quadruple high energy $\mathrm{Au}^{-}$ions were chosen in that study in order to create an homogenous thick damage layer of $~ 5 \mu \mathrm{m}$.[27] However, based on photoluminescence spectra and TEM results, the damage accumulation in xenotime $\left(\mathrm{YPO}_{4}\right)$ samples were observed to be heterogenous in the irradiated surface layer and that the amorphous fraction was observed to decrease unto a depth of $5 \mu \mathrm{m}$.[27] The heterogenous damage layer observed in the $\mathrm{YPO}_{4}$ ceramics were proposed to be a result of the epitaxial annealing occurring at the crystalline-amorphous interface.[27]

To the best of our knowledge, the impact of light-ions such as $\mathrm{He}^{+}$on the structure of pristine/amorphous xenotime has not been studied. In this regard, the present study aims to address the question whether $\alpha$-particles could induce a healing effect on the structure of amorphized xenotime and/or prevent the xenotime sample from undergoing amorphization. In this study, dual ion-beam irradiation $\left(\mathrm{Au}^{2+}[1.5 \mathrm{MeV}]+\mathrm{He}^{+}[160 \mathrm{keV}]\right)$ experiments were performed on xenotimetype $\mathrm{ErPO}_{4}$ ceramics and the structural response to ion-irradiation was monitored using in-situ TEM. $\mathrm{Au}^{2+}$ and $\mathrm{He}^{+}$ions were used to simulate the effects of recoil atom and $\alpha$-particle, respectively. In order to test the $\alpha$-healing capability of xenotime ceramics, high energy ions with varying ion-fluence $\left(\right.$ ions $/ \mathrm{cm}^{2}$ ) and flux (ions $/ \mathrm{cm}^{2} / \mathrm{s}$ ) were bombarded into thin lamella sections of $\mathrm{ErPO}_{4}$ ceramics in sequential $\left(\mathrm{Au}^{2+}\right.$ followed by $\mathrm{He}^{+}$ion-irradiation $)$and simultaneous $\left(\mathrm{Au}^{2+}+\right.$ $\mathrm{He}^{+}$ions) irradiation modes. The influence of electron beam on the damage recovery process in amorphized xenotime were also determined and will be discussed in this study. 


\section{Experimental Section}

\subsection{Synthesis and Sintering of $\mathrm{ErPO}_{4}$}

$\mathrm{ErCl}_{3 .} \mathrm{nH}_{2} \mathrm{O}$ (Sigma Aldrich, 99.9\%) and $\mathrm{H}_{3} \mathrm{PO}_{4}$ (Carlo Erba Reagents, 85\%) were used for the synthesis of $\mathrm{ErPO}_{4}$. Due to the hygroscopic character of $\mathrm{ErCl}_{3} \cdot \mathrm{nH}_{2} \mathrm{O}$, this solid was dissolved in 1 $\mathrm{M} \mathrm{HCl}$. The erbium concentration in solution was then determined using ICP-AES (Spectro Arcos EOP). Stoichiometric amount of $\mathrm{ErCl}_{3}$ was added dropwise to a beaker containing $\mathrm{H}_{3} \mathrm{PO}_{4}(10 \mathrm{~mol}$ $\%$ excess) and the solution was stirred for a few minutes before transferring the solution to a Teflon lined acid digestion vessel (Parr). The acid digestion vessel containing the solution mixture of erbium and phosphate ions were placed inside a conventional oven and heated to $250^{\circ} \mathrm{C}$ for 7 days. Pink colored precipitate was obtained and separated from the supernatant solution by centrifugation at $14000 \mathrm{rpm}$. The obtained powder was washed twice with deionized water and once with ethanol before being dried overnight in an oven at $90^{\circ} \mathrm{C}$. The phase purity of the assynthesized $\mathrm{ErPO}_{4}$ precipitate was checked using powder XRD data obtained from a Bruker D8 advance diffractometer equipped with a Lynxeye detector and $\mathrm{Cu} \mathrm{K} \alpha_{1,2}(\lambda=1.54184 \AA) \mathrm{X}$-ray source. The powder XRD patterns were collected over a wide $2 \theta$ range from $5^{\circ}-100^{\circ}$ using a step size of $0.019^{\circ}$ and the lattice constants of the as-synthesized material were determined using the HighScore Plus software program.[28] Rietveld refinement of the powder XRD pattern was performed using the xenotime-type $\mathrm{ErPO}_{4}$ structural model reported by Ni et al.[7] During the refinement, the following parameters were allowed to vary: scale factor, zero-shift, lattice constant, profile variables, and the overall isotropic thermal factor (B).

Prior to sintering, as-synthesized powders of $\mathrm{ErPO}_{4}$ were heated at $600^{\circ} \mathrm{C}$ for 3 hours to remove adsorbed water. Pre-heated powders of $\mathrm{ErPO}_{4}$ were ground and the fine powders were uniaxially pressed at $\sim 250 \mathrm{MPa}$ to obtain pellets of $\sim 5 \mathrm{~mm}$ in diameter. The pellets were sintered 
at $1600^{\circ} \mathrm{C}$ in air for 3 hours. The density of the sintered material is $97 \%$ of the theoretical density. The surface of the pellet was initially polished to reach an optical grade using a $5 \mu \mathrm{m} \mathrm{SiC} \mathrm{sheet}$ followed by a polishing of the surface using a finer $1 \mu \mathrm{m}$ diamond paste. The phase purity of the sintered material was determined by performing XRD experiments at the surface of the polished pellets of $\mathrm{ErPO}_{4}$.

\subsection{Focussed Ion Beam (FIB): Preparation of Lamellae}

Lamellas were prepared by FIB technique using a dual beam Scanning Electron Microscopy (SEM) equipped with a $\mathrm{Ga}^{+}$ion source (FEI Helios 600 NanoLab) located at the Centre Pluridisciplinaire de Microscopie electronique et de Microanalyse (CP2M) facility in Marseille, France. Prior to the lamella preparation, the surface of the sintered $\mathrm{ErPO}_{4}$ pellet was coated with a thin carbon layer to improve the sample conductivity which therefore enabled the collection of microstructural images from the sample using SEM. The region of the pellet from which the lamella was obtained was coated with a layer of Pt in order to protect the lamella from structural damage due to $\mathrm{Ga}^{+}$ion bombardment. The $\mathrm{Ga}^{+}$ion milling was initially carried out at an ion beam voltage of $30 \mathrm{kV}$ and ion beam currents ranging from $9 \mathrm{nA}$ to $90 \mathrm{pA}$. Thick sections of the lamella were removed using an Omniprobe 200 micromanipulator and transferred to a half copper grid wherein the final ion-milling step was performed at lower $\mathrm{Ga}^{+}$ion acceleration voltage $(5 \mathrm{kV})$ to minimize the ion damage. For the reasons mentioned above, a final cleaning step was also performed using $\mathrm{Ga}^{+}$ions at $2 \mathrm{kV}$ and $1 \mathrm{kV}$. Structural defects were observed at the surface of the lamella and can be found up to $\sim 500 \mathrm{~nm}$ below the surface. These surface defects are likely due to $\mathrm{Ga}^{+}$ion-milling of the pellet and/or due to mechanical polishing of the pellet prior to lamella preparation. Thus, the analysis of the effect of dual ion-beams on the lamella were carried out at regions far from the subsurface locations and in regions, wherein no structural defects were 
present. Six lamellas $(\sim 10.30 \times 5.40 \mu \mathrm{m})$ of varying thickness $(\sim 60-83 \mathrm{~nm})$ were prepared using the above-mentioned procedure were used for the ion irradiation experiments discussed in the following section.

\subsection{In-situ Dual Ion-Beam Implantation}

The ion irradiation experiments were performed at the Joint Accelerators for Nanosciences and Nuclear Simulation (JANNUS-Orsay) facility located at the Centre for Nuclear Sciences and Materials Sciences (CSNSM, Univ Paris-Sud/CNRS, Orsay, France). The JANNUS-Orsay facility is equipped with two ion accelerators (ARAMIS - 2 MV and IRMA - $190 \mathrm{kV}$ ). The ions coming off from these accelerators were transported via beamline to the in-situ TEM end station. In the present study, a $200 \mathrm{keV}$ in-situ TEM (FEI Tecnai $\mathrm{G}^{2} 20$ Twin) end-station was used to monitor the changes in the material structure due to ion-implantation under in-situ conditions. The thin lamella of pristine $\mathrm{ErPO}_{4}$ was first mounted on a double tilt GATAN sample holder before introducing the sample holder inside the TEM vacuum chamber for ion-irradiation. The ARAMIS and IRMA beamlines which were interfaced with the TEM instrument are separated by an angle of $45^{\circ}$ and each of these beamlines are oriented at an angle of $22^{\circ}$ with respect to the surface normal of the lamella.

In this study, thin lamellas of $\mathrm{ErPO}_{4}$ were irradiated with $1.5 \mathrm{MeV} \mathrm{Au}{ }^{2+}$ (ARAMIS) and 160 $\mathrm{keV} \mathrm{He}^{+}$(IRMA) ions of varying flux (ions $/ \mathrm{cm}^{2} / \mathrm{s}$ ) and fluence (ions $/ \mathrm{cm}^{2}$ ) and the structural changes were studied using in-situ TEM. The temperature of the TEM foil was also measured simultaneously during ion-irradiation. The energies deposited by $\mathrm{He}^{+}$and $\mathrm{Au}^{2+}$ ions into the lamella had contributions from both electronic $\left(E_{\text {electronic }}\right.$ in $\left.\mathrm{keV} / \mathrm{cm}^{3}\right)$ and nuclear $\left(E_{\text {nuclear }}\right.$ in $\mathrm{keV} / \mathrm{cm}^{3}$ ) process. The values of $\mathrm{E}_{\text {electronic }}$ and $\mathrm{E}_{\text {nuclear }}$ were derived from the nuclear and electronic stopping powers of $\mathrm{Au}^{2+}$ and $\mathrm{He}^{+}$ions (expressed in $\mathrm{keV} / \mathrm{nm}$ ) calculated using Stopping and Range 
of Ions in Matter (SRIM-2013) software (Table 1). The projected range of these ions in the lamella were calculated using the SRIM-2013 software. The ratio of electronic to nuclear stopping powers (ENSP) for single ion-beam $\left(\mathrm{Au}^{2+}, \mathrm{He}^{+}\right)$and dual ion-beam $\left(\mathrm{Au}^{2+}+\mathrm{He}^{+}\right)$irradiation are presented in Table 1. The stopping power of $\mathrm{Au}^{2+}$ and $\mathrm{He}^{+}$ions can be considered as a constant in the entire thickness of the lamella and hence, the ENSP ratio is equivalent to $E_{\text {electronic/ }} E_{\text {nuclear. }}$ Similarly, the number of displacements per atom (dpa) in the lamella caused by ion-irradiation were also determined using SRIM-2013 software. The displacement energies of Er, P, and O used for the SRIM simulation are $25 \mathrm{eV}, 25 \mathrm{eV}$, and $28 \mathrm{eV}$, respectively.

Multiple ion-irradiation experiments were performed in sequential (i.e., $\mathrm{Au}^{2+}$ ion irradiation followed by $\mathrm{He}^{+}$ion irradiation) and simultaneous (i.e., $\mathrm{Au}^{2+}+\mathrm{He}^{+}$) modes. Sequential irradiation experiments were performed to determine whether $\alpha$-particle irradiation could initiate a structural recovery process in amorphous xenotime. It must be noted that at lower $\mathrm{He}^{+}$ion fluences $\left(3 \times 10^{13}\right.$ ions $\left./ \mathrm{cm}^{2}, 5.4 \times 10^{-4} \mathrm{dpa}\right)$, the $\mathrm{He}^{+}$ions lose energy largely via ionization process and does not initiate atomic displacements in the structure. However, at higher ion fluences $\left(2.87 \times 10^{17}\right.$ ions $/ \mathrm{cm}^{2}, 5.1 \mathrm{dpa}$ ), the $\mathrm{He}^{+}$ions will lose energy via ionization and ballistic process and can initiate atomic displacements in the structure. On the other hand, simultaneous irradiation experiments were performed to determine whether $\alpha$-particles could prevent the xenotime sample from undergoing amorphization. In sequential mode, one of the six $\mathrm{ErPO}_{4}$ lamellas, was irradiated with $\mathrm{Au}^{2+}$ ions up to a fluence of $2 \times 10^{14}$ ions $/ \mathrm{cm}^{2}$ followed by irradiation with $\mathrm{He}+$ ions up to a fluence of $1 \times 10^{17}$ ions $/ \mathrm{cm}^{2}$ (Table 2). Post-irradiation, BF-TEM images and SAED patterns were collected from the irradiated lamella. In simultaneous mode, four $\mathrm{ErPO}_{4}$ lamellas were irradiated simultaneously with $\mathrm{Au}^{2+}$ and $\mathrm{He}^{+}$ions with varying ion-fluence, flux, and ratios of $\mathrm{E}_{\text {electronic }} / \mathrm{E}_{\text {nuclear }}$ (See Tables 3 and 4 for experimental details). In all of the above-mentioned experiments, the 
electron beam was switched off during ion-irradiation in order to prevent the sample from undergoing an electron-induced damage recovery process. The effect of electron beam on the structure of amorphized xenotime was also determined in this study via sequential irradiation $\left(\mathrm{Au}^{2+}\right.$ followed by $\mathrm{e}^{-}$beam) of the lamella (See Table 5 for experimental details). The pristine lamella was first irradiated with $\mathrm{Au}^{2+}$ ions to a fluence of $1 \times 10^{14}$ ions $/ \mathrm{cm}^{2}$ followed by exposure to $\mathrm{e}^{-}$ beam for $\sim 4.3$ hours (Table 5). The BF-TEM images and SAED patterns were recorded from the lamella at frequent time-intervals to monitor the damage recovery due to electron beam (Figure 9).

\section{Results and Discussion}

\subsection{Structure: Before ion-irradiation}

The powder XRD pattern of the sintered $\mathrm{ErPO}_{4}$ material from which the thin lamellas were obtained are presented in Figure 2. $\mathrm{ErPO}_{4}$ adopted the xenotime-type structure and the lattice constants of $\mathrm{ErPO}_{4}$ obtained through the Rietveld refinement of the powder XRD data are presented in Table 6. Prior to performing the ion irradiation on $\mathrm{ErPO}_{4}, \mathrm{BF}-\mathrm{TEM}$ images and SAED patterns were collected from the pristine lamellas (Figure 3). The BF-TEM image of pristine lamella clearly revealed the presence of grains and grain boundaries (Figure 3). The SAED pattern of the pristine lamella contains sharp diffraction spots thereby indicating the high crystallinity of the material (Figure 3).

\subsection{Structure: After ion-irradiation}

\subsubsection{Sequential Irradiation}

The pristine $\mathrm{ErPO}_{4}$ lamella was initially irradiated with $\mathrm{Au}^{2+}$ ions to a lower fluence of $1 \times 10^{13}$ ions $/ \mathrm{cm}^{2}(0.04 \mathrm{dpa})$ followed by increasing the fluence to $5 \times 10^{13}(0.20 \mathrm{dpa}), 1 \times 10^{14}(0.40 \mathrm{dpa})$, and $2 \times 10^{14}$ ions $/ \mathrm{cm}^{2}(0.82 \mathrm{dpa})$. The ion-fluences were increased progressively in order to 
increase the amount of nuclear energy deposited in the lamella. The BF-TEM images and the corresponding SAED patterns of the lamella irradiated to various ion-fluences were recorded (Figure 4). In comparison to the pristine lamella, the lamella irradiated to $1 \times 10^{13}$ ions $/ \mathrm{cm}^{2}$ exhibited little or no sign of radiation damage and retained its crystallinity as indicated by the observation of the grains (and grain boundaries) as well as the presence of sharp diffraction spots in the SAED pattern (cf. Figures 3 and 4a). This observation indicated that at a lower fluence of 1 $\times 10^{13}$ ions $/ \mathrm{cm}^{2}$, the amount of nuclear energy $\left(E_{\text {nuclear }}=5.3 \times 10^{20} \mathrm{keV} / \mathrm{cm}^{3}\right)$ deposited in the lamella by the $\mathrm{Au}^{2+}$ ions was not enough to initiate a large number of atomic displacements in the structure. Upon increasing the $\mathrm{Au}^{2+}$ ion fluence to $5 \times 10^{13} \mathrm{ions} / \mathrm{cm}^{2}\left(\mathrm{E}_{\text {nuclear }}=2.3 \times 10^{21} \mathrm{keV} / \mathrm{cm}^{3}\right)$, the material became amorphous as is evident from the disappearance of grains in the lamella (and the presence of homogenous contrast in the BF-TEM image) and the observation of diffuse rings in the corresponding SAED pattern (Figure $4 \mathrm{~b}$ ). Ion-irradiation using $\mathrm{Au}^{2+}$ ions would usually result in the production of point defects (e.g., vacancies and interstitials) and the concentration of these defects is expected to increase with increasing $\mathrm{Au}^{2+}$ ion fluence. The smaller ENSP ratio of $\mathrm{Au}^{2+}$ ion-irradiation suggests a greater accumulation of point defects and consequently, the number of isolated amorphous domains in the structure would increase and begin to overlap thereby rendering the structure completely amorphous (Table 1 and Figure 4b).[2] The $\mathrm{ErPO}_{4}$ material continued to remain amorphous upon increasing the $\mathrm{Au}^{2+}$ ion fluence to $1 \times 10^{14}$ ions $/ \mathrm{cm}^{2}\left(\mathrm{E}_{\text {nuclear }}\right.$ $\left.=4.7 \times 10^{21} \mathrm{keV} / \mathrm{cm}^{3}\right)$ and $2 \times 10^{14}$ ions $/ \mathrm{cm}^{2}\left(\mathrm{E}_{\text {nuclear }}=9.4 \times 10^{21} \mathrm{keV} / \mathrm{cm}^{3}\right)($ Figure $4 \mathrm{c})$. It should be noted that under identical ion-irradiation conditions, the monazite $\left(\mathrm{LaPO}_{4}\right)$ material was found to remain partially crystalline up to $1 \times 10^{14}$ ions $/ \mathrm{cm}^{2}$ before becoming completely amorphous at a fluence of $2 \times 10^{14}$ ions $/ \mathrm{cm}^{2}$.[20] This comparison showed that the xenotime $\left(\mathrm{ErPO}_{4}\right)$ structure, which amorphized at a much lower ion-fluence $\left(5 \times 10^{13}\right.$ ions $\left./ \mathrm{cm}^{2}\right)$, exhibit a greater ease of 
amorphization compared to the monazite structure $\left(\mathrm{LaPO}_{4}\right)$. The susceptibility of a material to amorphization could be explained using the topological model proposed by Hobbs.[29] Hobbs model states that materials having a higher connectivity of the cation polyhedra are structurally constrained and hence, less susceptible to radiation-induced amorphization.[29] In the xenotime structure, the individual $\mathrm{REO}_{8}$ polyhedra are connected to the four neighbouring $\mathrm{REO}_{8}$ polyhedra via edge-sharing whereas in the monazite structure, the $\mathrm{REO}_{9}$ polyhedra are connected to six neighbouring $\mathrm{REO}_{9}$ polyhedra via edge-sharing.[2,7] Thus, the average connectivity of the $\mathrm{REO}_{8}$ and $\mathrm{REO}_{9}$ polyhedra in the xenotime and monazite structures are 4 and 6 , respectively. Based on Hobbs model, the xenotime structure, which has a lower connectivity of the $\mathrm{REO}_{8}$ polyhedra, is structurally less constrained than the monazite structure and hence, can be amorphized at a lower ion-fluence.

As outlined in Section 1, the natural xenotime minerals investigated by Svecova et al. were found to be present in a partially crystalline state and were never found in a fully amorphous state.[14] However, it was shown in this study that the synthetic xenotime $\left(\mathrm{ErPO}_{4}\right)$ was amorphized upon $\mathrm{Au}^{2+}$ ion irradiation at a lower ion-fluence. The different radiation response of synthetic and natural xenotime samples could be explained by considering the effects of recrystallization that could occur in natural xenotime minerals. Similar to natural monazite minerals, recrystallization in natural xenotime minerals could be initiated either by thermal annealing or via $\alpha$-annealing of amorphous regions. Electronic energy deposition during $\alpha$-particle or other light-ion irradiation could also provide sufficient energy for the recombination of point defects (e.g., vacanciesinterstitial recombination) produced due to $\alpha$-recoil atom. As is demonstrated for synthetic monazite samples $\left(\mathrm{LaPO}_{4}\right)$ by Seydoux-Guillaume et al., the electronic energy deposited during $\alpha$-particle irradiation induced the recrystallization of amorphous regions in the monazite 
samples.[20] Debelle et al. also observed the recrystallization of amorphous $\mathrm{SiC}$ ceramics upon irradiation using swift heavy ions in the electronic energy loss regime.[30] Similarly, in the study reported by Zinkle, the effect of electronic energy deposition on the microstructure of $\mathrm{MgAl}_{2} \mathrm{O}_{4}$ spinel oxides was discussed.[31-33] Here, dislocation loops were observed in both the heavy- and light-ion irradiated regions of the samples. However, it was shown that the rate of formation and the density of dislocation loops due to heavy-ion irradiation was higher in comparison to light-ion irradiation of spinel oxides and the mechanism for such retardation of formation of dislocation loops was proposed by Yasuda et al.[31-34] In that study, it was shown that the ionizing radiation (light-ion and electron irradiation) promotes the dissociation of dislocation loops into interstitial atoms which then recombine with the vacancies generated during the ion-irradiation.[34]

In order to determine the effect of electronic energy deposition on amorphous xenotime, the amorphized $\mathrm{Au}^{2+}$ ion-irradiated $\mathrm{ErPO}_{4}$ was irradiated with $\mathrm{He}^{+}$ions to ion fluences ranging from $3 \times 10^{13} \mathrm{ions} / \mathrm{cm}^{2}\left(\right.$ Eelectronic $\left.=1.2 \times 10^{20} \mathrm{keV} / \mathrm{cm}^{3}\right)$ to $1 \times 10^{17} \mathrm{ions} / \mathrm{cm}^{2}\left(\right.$ Eelectronic $=3.4 \times 10^{23}$ $\mathrm{keV} / \mathrm{cm}^{3}$ ) (See Table 2 and Figure 4d). The ENSP ratio of $\mathrm{He}^{+}$ion irradiation was much higher than those of $\mathrm{Au}^{2+}$ ion irradiation and as a result, $\mathrm{He}^{+}$ion-irradiation of amorphous $\mathrm{ErPO}_{4}$ would result in a lower accumulation of defects, due to the greater mobility of point defects (Table 1).[2] The temperature of the TEM foil was measured after each step of $\mathrm{He}^{+}$ion-irradiation and were found to be $25^{\circ} \mathrm{C}$ (Steps $5-9$, Table 2), $28^{\circ} \mathrm{C}$ (Steps $10-12$, Table 2), and $55^{\circ} \mathrm{C}$ (Steps $13-14$, Table 2). It should be noted that the temperature of the foil was cooled down to $25^{\circ} \mathrm{C}$ prior to the collection of BF-TEM images. As is observed from BF-TEM images and their corresponding SAED patterns, the electronic energy deposited in the lamella due to $\mathrm{He}^{+}$ion irradiation did not bring about the structural recovery of amorphous xenotime (Figure 4d). Unlike xenotime samples, evident signs of recrystallization of the amorphous monazite upon $\mathrm{He}^{+}$ion $(160 \mathrm{keV})$ irradiation 
were observed at ion-fluences starting from $4 \times 10^{16} \mathrm{ions} / \mathrm{cm}^{2}$ and was attributed to the electronic energy loss of $\mathrm{He}^{+}$ions in the sample.[20] It is proposed in this study that the activation energy barrier for the transformation of amorphous to crystalline state could be higher for the xenotime structure than those of the monazite structure.[2] Therefore, the electronic energy deposited in amorphous $\mathrm{ErPO}_{4}$ during $\mathrm{He}^{+}$ion irradiation was not sufficient to overcome the activation energy barrier and hence, the xenotime materials continued to remain in the amorphous state. However, it is also possible that the $\mathrm{He}^{+}$ion irradiation should be performed simultaneously with $\mathrm{Au}^{2+}$ ion irradiation in order to observe the recrystallization in synthetic xenotime samples. Simultaneous irradiation of synthetic $\mathrm{ErPO}_{4}$ with $\mathrm{Au}^{2+}$ and $\mathrm{He}^{+}$ions better simulates the radiation conditions experienced by the natural xenotime mineral. Therefore, simultaneous ion-irradiation experiments were performed on synthetic $\mathrm{ErPO}_{4}$.

\subsubsection{Simultaneous Irradiation}

Simultaneous ion-irradiation of $\mathrm{ErPO}_{4}$ lamella using $\mathrm{Au}^{2+}$ and $\mathrm{He}^{+}$ions allows for a study of the combined effects of $\alpha$-decay products (recoil atom and $\alpha$-particle) on the xenotime structure. In a recent review by Weber et al., the synergistic effects of the electronic and nuclear energy losses on the microstructure of materials has been discussed.[35] In the current study, the primary aim of performing simultaneous ion irradiation experiments was to determine whether $\alpha$-particles could prevent the xenotime structure from amorphization and in this regard, four experiments were performed in which the lamellas of $\mathrm{ErPO}_{4}$ were simultaneously irradiated using an identical flux of $\mathrm{Au}^{2+}$ ions $\left(2 \times 10^{10}\right.$ ions $\left./ \mathrm{cm}^{2} / \mathrm{s}\right)$ and a varying flux of $\mathrm{He}^{+}$ions $\left(3 \times 10^{12}, 5 \times 10^{12}, 1.4 \times 10^{13}\right.$,

and $2.9 \times 10^{13}$ ions $\left./ \mathrm{cm}^{2} / \mathrm{s}\right)$. In this manner, the amount of electronic energy $\left(\mathrm{E}_{\text {electronic }}\right.$ in $\left.\mathrm{keV} / \mathrm{cm}^{3}\right)$ deposited in the lamella was varied in each of the four experiments (See Tables 3 and 4). The 
amount of electronic energy (Eelectronic) deposited in the lamella was increased on going from one experiment to another thereby resulting in an increase in the ratio of $\mathrm{E}_{\text {electronic }} / \mathrm{E}_{\text {nuclear. }}$.

In the first experiment $\left(\mathrm{E}_{\text {electronic }} / \mathrm{E}_{\text {nuclear }}=10\right)$, the lamella which was initially irradiated to 1 $\times 10^{13} \mathrm{Au}^{2+}$ ions $/ \mathrm{cm}^{2}$ and $1.4 \times 10^{15} \mathrm{He}^{+}$ions $/ \mathrm{cm}^{2}$ did not exhibit any sign of amorphization and the material is found to remain in the crystalline state as is evident from their BF-TEM image and SAED pattern (Figure 5b). However, the mottled diffraction contrasts observed in the BF-TEM image indicated the early stages of structural damage (i.e., onset of crystalline to amorphous transition) in the xenotime structure due to the $\alpha$-recoil atom.[36,37] The diffraction contrasts could arise primarily from the presence of strain fields and point defects (Frenkel defects) surrounding isolated $\alpha$-recoil and $\alpha$-particle tracks (Figure 5b).[36,37] Subsequently, the $\mathrm{Au}^{2+}$ and $\mathrm{He}^{+}$ion fluences were increased by an order of magnitude up to $1 \times 10^{14} \mathrm{ions} / \mathrm{cm}^{2}$ and $1.5 \times 10^{16}$ ions $/ \mathrm{cm}^{2}$, respectively, in two steps (Table 3). Analysis of the BF-TEM images and SAED patterns recorded from the lamellas irradiated to higher $\mathrm{Au}^{2+}+\mathrm{He}^{+}$ion fluences revealed a complete loss of crystallinity (See Figures $5 \mathrm{c}$ and $5 \mathrm{~d}$ ). This structural transformation from crystalline to amorphous state was a result of accumulation and overlap of the $\alpha$-recoil tracks.[36,37]

The amount of electronic energy deposited in the lamella was increased in the second experiment $\left(E_{\text {electronic }} / \mathrm{E}_{\text {nuclear }}=17-18\right)$ and the lamella was irradiated to a total of $1 \times 10^{14} \mathrm{Au}^{2+}$ ions $/ \mathrm{cm}^{2}$ and $2.78 \times 10^{16} \mathrm{He}^{+}$ions $/ \mathrm{cm}^{2}$ in two steps (Figure 6). The lamella irradiated to $1 \times 10^{13}$ $\mathrm{Au}^{2+}$ ions $/ \mathrm{cm}^{2}$ and $2.83 \times 10^{15} \mathrm{He}^{+}$ions $/ \mathrm{cm}^{2}$ retained its crystallinity and only, mottled diffraction contrasts due to the presence of point defects were observed in the BF-TEM image (Figures $6 \mathrm{~b}$ and $6 \mathrm{c})$. The lamella that was irradiated to $5 \times 10^{13} \mathrm{Au}^{2+}$ ions $/ \mathrm{cm}^{2}$ and $1.35 \times 10^{16} \mathrm{He}^{+}$ions $/ \mathrm{cm}^{2}$ was largely amorphous as indicated by the presence of diffuse halo rings in the SAED pattern (Figure 6d). However, the presence of two diffraction spots (marked by red arrows) in the SAED 
pattern indicated that the material was not completely amorphous (Figure 6d). The material became completely amorphous upon increasing the $\mathrm{Au}^{2+}$ and $\mathrm{He}^{+}$ion fluences to $1 \times 10^{14}$ ions $/ \mathrm{cm}^{2}$ and $2.78 \times 10^{16}$ ions $/ \mathrm{cm}^{2}$, respectively (Figures 6e and 6f). It is worth noting that under similar dual ion-beam irradiation conditions $\left(E_{\text {electronic }} / E_{\text {nuclear }}=13-15\right)$, the monazite samples did not undergo a structural transformation to the amorphous state and remained crystalline for all the ion fluences studied.[20] Based on these observations, it can be inferred that the electronic energy deposited in the $\mathrm{ErPO}_{4}$ lamella was not enough to prevent the material from undergoing a radiation-induced amorphization process.

In the subsequent experiments, higher amounts of electronic energy were deposited in the lamella $\left(E_{\text {electronic }} / E_{\text {nuclear }}=36-39\right.$ and $\left.54-57\right)$ by increasing the ion fluxes and fluences of $\mathrm{He}^{+}$ ions (Figures 7 and 8). It must be noted that for higher $E_{\text {electronic }} / E_{\text {nuclear }}$ ratios, the nuclear energy loss component of the $\mathrm{He}^{+}$ion is not negligible and is comparable to those of $\mathrm{Au}^{2+}$ ions. Hence, $\mathrm{He}^{+}$ion-irradiation could also initiate atomic displacements in $\mathrm{ErPO}_{4}$. Evidence of $\alpha$-healing (i.e., $\alpha$-particle assisted healing of structural defects) of the xenotime structure was observed in the third experiment $\left(E_{\text {electronic }} / E_{\text {nuclear }}=36-39\right)$ in which mixtures of both crystalline and amorphous domains were observed in the lamella irradiated up to $1.5 \times 10^{14} \mathrm{Au}^{2+}$ ions $/ \mathrm{cm}^{2}$ and $1.06 \times 10^{17}$ $\mathrm{He}^{+}$ions $/ \mathrm{cm}^{2}$ (Figures $7 \mathrm{~b}-7 \mathrm{e}$ ). This observation implied that the electronic energy deposited during $\mathrm{He}^{+}$ion-irradiation initiated a partial recovery of the structure. On further increase in the $\mathrm{Au}^{2+}\left(2 \times 10^{14}\right.$ ions $\left./ \mathrm{cm}^{2}\right)$ and $\mathrm{He}^{+}\left(1.4 \times 10^{17}\right.$ ions $\left./ \mathrm{cm}^{2}\right)$ ion fluences, the material underwent a complete structural transformation to the amorphous state and $\alpha$-healing of the damaged xenotime structure was not observed (Figure 7f). Consequently, the electronic energy deposition in the lamella was increased in the fourth experiment $\left(E_{\text {electronic }} / E_{\text {nuclear }}=54-57\right)$ and the material did not exhibit any signs of radiation-induced amorphization for all the ion fluences studied (Figure 8). 
Barring the mottled diffraction contrasts in the lamella attributed to radiation-induced lattice strain and point defects, the xenotime-type $\mathrm{ErPO}_{4}$ remained crystalline at all ion fluences thus demonstrating the capability of $\alpha$-particles in preventing the xenotime structure from undergoing amorphization process (Figures $8 b-8 i$ ). The underlying reason for the prevention of amorphization of xenotime ceramics at higher $E_{\text {electronic }} / E_{\text {nuclear }}$ ratios was due to $\alpha$-healing mechanism. The healing of structural defects can be attributed to a multitude of factors such as increase in the local temperature of the material due to $\alpha$-particles irradiation, ionization-enhanced diffusion of point defects, and vacancy-interstitial recombination.[23,31-34] It was shown conclusively from the dual-ion beam experiments on xenotime samples, that the $\alpha$-healing mechanism, which was experimentally demonstrated for monazite samples, was also responsible for the prevention of amorphization in the xenotime samples.[20] It should be noted that unlike monazite, the $\alpha$-healing mechanism in the xenotime structure was evident only upon increasing the amount of electronic energy deposition in the lamella.

\subsubsection{Electron Beam Irradiation}

Previous studies on in-situ TEM observations of ion-irradiated nuclear wasteforms demonstrated the structural healing ability of electrons. In this study, the electron beams were switched off during the time of ion-irradiation in sequential and simultaneous experiments in order to minimize the impact (if any) of electron beams on the structure of xenotime.[20,38] However, electron beams were used for a short period of time to monitor the structural response of post-irradiated samples and it was important to decipher whether electron beams had some contribution to the recrystallization of amorphous xenotime that was observed in the dual ion-beam experiments. In order to address this question, the pristine $\mathrm{ErPO}_{4}$ lamella was completely amorphized using $\mathrm{Au}^{2+}$ ions, as in previous experiments, and only a small area of the foil was then exposed to the electron 
beams $(200 \mathrm{keV})$ with varying electron flux $\left(270-5040 \mathrm{e}^{-} \mathrm{nm}^{-2} \mathrm{~s}^{-1}\right)$ for a total time-period of 4.3 hours (Figure 9). The electronic stopping power of electrons is $1.5 \mathrm{eV} / \mathrm{nm}$ and the electronic energy deposited in the lamella due to electrons varied from $2.18 \times 10^{24} \mathrm{keV} / \mathrm{cm}^{3}\left(\mathrm{e}^{-}\right.$flux: $270 \mathrm{e}^{-} \mathrm{nm}^{-2} \mathrm{~s}^{-1}$; time: $90 \mathrm{mins}$ ) to $1.17 \times 10^{26} \mathrm{keV} / \mathrm{cm}^{3}$ (e flux: $5040 \mathrm{e}^{-} \mathrm{nm}^{-2} \mathrm{~s}^{-1}$; time: $260 \mathrm{mins}$ ). The Eelectronic deposited in the amorphous $\mathrm{ErPO}_{4}$ due to the electron beam is $4-6$ orders of magnitude higher than the $\mathrm{E}_{\text {electronic }}$ deposited during $\mathrm{He}^{+}$ion-irradiation of amorphous $\mathrm{ErPO}_{4}$ (See Tables 2 and 5). Crystallization of the amorphous domains started after exposure to electron beam as evidenced by the appearance of nuclei in the lamella (Figure 9d). Indexing of the electron diffraction pattern conclusively showed that the recrystallized nuclei are xenotime crystallites (See Figure 10 and Table 7). The $\mathrm{d}_{\mathrm{hkl}}$ values determined in this study were compared with those reported by Ni et al. (Table 7).[7] Electron beam induced recrystallization occurred after $\sim 2$ hrs of exposure to the electron beam. This observation clearly demonstrated that the recrystallization observed in dual ion-beam experiments was exclusively due to $\alpha$-particle irradiation since the TEM images and SAED patterns were collected immediately after the ion-irradiation in less than $\sim 1$ hour. It should also be noted that the electron flux used to observe the lamella after dual-ion beam irradiation was much lower than the electron flux used for the electron irradiation experiment (Table 5).

The concentration of the recrystallized nuclei increased slowly as a function of electron beam exposure time and electron flux (Figure 9d-9i). Because of the slower nucleation rate, large crystals of xenotime were observed in the lamella upon exposure to electron beam (See Figure 9i). In the study reported by Seydoux-Guillaume et al., electron irradiation experiments performed on amorphized $\mathrm{LaPO}_{4}$ (monazite) lamella also yielded similar results that were observed for $\mathrm{ErPO}_{4}$ (xenotime) in this study.[20] However, the nucleation rate was faster for monazite samples as indicated by the appearance of the first nuclei after $~ 25$ minutes of exposure to electron beam.[20] 
Due to the faster rate of nucleation, only smaller sized nuclei were observed upon exposure of amorphous monazite samples to electron beam.[20] These observations confirmed that the activation energy for the recrystallization of xenotime structure was higher than the monazite structure and is in good agreement with the results reported by Meldrum et al.[2] Global view of the entire lamella after the electron irradiation experiment clearly reveal the presence of two regions (Figure 11). The region exposed to the electron beam underwent an electron-induced amorphous to crystalline transformation while the region not exposed to the electron beam remained amorphous (Figure 11). This observation clearly showed that the electron beams could also induce recrystallization of amorphous xenotime samples and that the efficiency of electronbeam induced recrystallization process was lower for the xenotime structure in comparison to the monazite structure.

\subsection{Dual Ion-Beam Radiation Response : Monazite vs Xenotime}

Comparison of the dual ion-beam radiation response of monazite and xenotime structures was made by comparing the results from this study with those obtained from a similar study carried out on monazite $\left(\mathrm{LaPO}_{4}\right)$ samples by Seydoux et al.[20] In order to facilitate this comparison, the electronic energy deposited in the $\mathrm{ErPO}_{4}$ and $\mathrm{LaPO}_{4}$ lamellas due to ion-implantation were plotted against the corresponding nuclear energies (Figure 12). For the xenotime structure, complete amorphization of the structure was observed for lower $E_{\text {electronic }} / E_{\text {nuclear }}$ ratios $\left(\mathrm{E}_{\text {electronic }} / \mathrm{E}_{\text {nuclear }}=9\right.$

$-10 \& 16-18$, Figure 12) and the metamictization of the xenotime structure was completely prevented upon increasing the amount of electronic energy deposited in the lamella $\left(E_{\text {electronic }} / E_{\text {nuclear }}=54-57\right.$, Figure 12). Unlike xenotime, the monazite structure was not amorphized for lower $E_{\text {electronic }} / E_{\text {nuclear }}$ ratios $\left(E_{\text {electronic }} / E_{\text {nuclear }}=13-15\right.$; See Figure 12) and remain in the crystalline state at all the ion-fluences studied.[20] Based on these observations, prevention 
of metamictization of the xenotime structure would require $\sim 4$ times the electronic energy deposition required for the prevention of amorphization of the monazite structure.

The different structural response to dual ion-beam irradiation could be attributed to the differences in the crystal structures of monazite and xenotime materials.[7] In the monazite structure, the $\mathrm{REO}_{9}$ polyhedra is irregular and distorted. Due to the distorted nature of the $\mathrm{REO}_{9}$ polyhedra, it is proposed in this study that the amorphized monazite samples would require lower amounts of electronic energy to return to its original crystalline state. As a result, the monazite samples did not undergo a radiation-induced amorphization for lower $E_{\text {electronic/ }} / E_{\text {nuclear }}$ ratios $\left(E_{\text {electronic }} / \mathrm{E}_{\text {nuclear }}=13-15\right.$, Figure 12). On the contrary, the xenotime structure is characterized by a more symmetrical $\mathrm{REO}_{8}$ polyhedra. Considering the symmetric nature of the $\mathrm{REO}_{8}$ polyhedra, it is proposed that the amorphized xenotime samples would require large amounts of electronic energy in order to undergo a structural reorganization. As it was shown in this study, the amorphization of xenotime structure can be completely prevented only upon deposition of large amounts of electronic energy ( Eelectronic $E_{\text {nuclear }}=54-57$, Figure 12). Based on these observations, it is proposed that the amorphous monazite sample exhibited a greater ease of structural recovery due to $\alpha$-particles than the xenotime sample.

\section{Conclusion}

The effect of dual ion beam irradiation on the structure of xenotime-type $\mathrm{ErPO}_{4}$ was investigated in this study using in-situ TEM. Multiple ion-irradiation experiments were carried out in which thin lamellas of $\mathrm{ErPO}_{4}$, obtained using the FIB technique, was irradiated with $\mathrm{Au}^{2+}(1.5 \mathrm{MeV})$ and $\mathrm{He}^{+}(160 \mathrm{keV})$ ion beams in sequential $\left(\mathrm{Au}^{2+}\right.$ followed by $\left.\mathrm{He}^{+}\right)$and simultaneous $\left(\mathrm{Au}^{2+}+\mathrm{He}^{+}\right)$ modes. Sequential ion-irradiation experiments showed that the xenotime structure was amorphized at a lower $\mathrm{Au}^{2+}$ ion-fluence in comparison to the monazite structure and that the subsequent $\mathrm{He}^{+}$ 
ion-irradiation of amorphized $\mathrm{ErPO}_{4}$ samples did not result in the structural recovery of xenotime. On the contrary, the simultaneous ion-irradiation experiments showed that the $\mathrm{He}^{+}$ions prevented the xenotime structure from undergoing radiation-induced amorphization events thereby demonstrating the presence of $\alpha$-healing mechanism in xenotime samples. Unlike the monazite samples wherein the $\alpha$-healing mechanism was observed for lower $E_{\text {electronic }} / E_{\text {nuclear }}$ ratios $\left(\mathrm{E}_{\text {electronic }} / \mathrm{E}_{\text {nuclear }}=13-15\right)$, the $\alpha$-healing mechanism was observed in xenotime samples only upon deposition of $\sim 4$ times the amount of electronic energy required for the monazite structure $\left(E_{\text {electronic }} / E_{\text {nuclear }}=54-57\right)$. Thus, the xenotime structure was less efficient towards $\alpha$-particle and electron-induced recrystallization events than the monazite structure. The different response of these materials to ion-irradiation are attributed to the different crystal structures of monazite and xenotime materials. The results obtained from this study will contribute to the growing database of candidate ceramic materials proposed for the immobilization of long-lived radionuclides.

\section{Acknowledgement}

The authors would like to thank the French National Research Agency (ANR JCJC-X-MAS; Project \# ANR-17-CE06-0004) for the financial support. The ion-irradiation experiments performed at the CSNSM facility: JANNuS-Orsay (CSNSM Univ Paris-Sud/ CNRS, Orsay, France) was supported by the EMIR French accelerator network. The authors would also like to thank Dr. Nicolas Clavier for discussions about the sintering procedure for $\mathrm{ErPO}_{4}$ samples. 


\section{References}

[1] A. J. Anderson, K. V Hodges, M. C. van Soest, J.M. Hanchar, Helium Diffusion in Natural Xenotime, Geochemistry, Geophysics, Geosystems. 20 (2019) 417-433.

[2] A. Meldrum, L. Boatner, R. Ewing, Displacive radiation effects in the monazite- and zircon-structure orthophosphates, Phys. Rev. B. 56 (1997) 13805-13814.

[3] L. A. Boatner, Synthesis, Structure, and Properties of Monazite, Pretulite, and Xenotime, Rev. Mineral. Geochemistry. 48 (2002) 87-121.

[4] D. E. Harlov, W. Richard, Experimental incorporation of Th into xenotime at middle to lower crustal P-T utilizing alkali-bearing fluids, Am. Mineral. 97 (2012) 641.

[5] A. C. Palke, J. F. Stebbins, Paramagnetic interactions in the ${ }^{31} \mathrm{P}$ NMR spectroscopy of rare earth element orthophosphate $\left(\mathrm{REPO}_{4}\right.$, monazite/xenotime) solid solutions, Am. Mineral. 96 (2011) 1343-1353.

[6] R. Gratz, W. Heinrich, Monazite-xenotime thermobarometry; experimental calibration of the miscibility gap in the binary system $\mathrm{CePO}_{4}-\mathrm{YPO}_{4}$, Am. Mineral. 82 (1997) $772-780$.

[7] Y. Ni, J. M. Hughes, A. N. Mariano, Crystal chemistry of the monazite and xenotime structures, Am. Mineral. 80 (1995) 21-26.

[8] A. D. Vasconcelos, G. O. Gonçalves, C. Lana, I. S. Buick, S. L. Kamo, F. Corfu, R. Scholz, A. Alkmim, G. Queiroga, H. A. Nalini Jr., Characterization of Xenotime From Datas (Brazil) as a Potential Reference Material for In Situ U-Pb Geochronology, Geochemistry, Geophysics, Geosystems. 19 (2018) 2262-2282.

[9] F. S. Spear, J. M. Pyle, Apatite, Monazite, and Xenotime in Metamorphic Rocks, Rev. Mineral. Geochemistry. 48 (2002) 293 - 335.

[10] A. M. Seydoux-Guillaume, R. Wirth, W. Heinrich, J. M. Montel, Experimental determination of Thorium partitioning between monazite and xenotime using analytical electron microscopy and X-ray diffraction Rietveld analysis, Eur. J. Mineral. 14 (2002) 869-878.

[11] H. Forster, The chemical composition of REE-Y-Th-U-rich minerals in peraluminous accessory granites of the Erzgebirge-Fichtelgebirge region, Germany; Part II : Xenotime, Am. Mineral. 83 (1998) 1302-1315.

[12] B. van Emden, M.R. Thornber, J. Graham, F.J. Lincoln, The incorporation of actinides in monazite and xenotime from placer deposits in Western Australia, Can. Mineral. 35 (1997) $95-104$.

[13] G. Franz, G. Andrehs, D. Rhede, Crystal chemistry of monazite and xenotime from Saxothuringian-Moldanubian metapelites, NE Bavaria, Germany, Eur. J. Mineral. 8 (1996) 1097-1118.

[14] E. Švecová, R. Čopjaková, Z. Losos, R. Škoda, L. Nasdala, J. Cícha, Multi-stage evolution of xenotime--(Y) from Písek pegmatites, Czech Republic: an electron probe micro-analysis and Raman spectroscopy study, Mineral. Petrol. 110 (2016) 747-765. 
[15] A. M. Seydoux-Guillaume, R. Wirth, L. Nasdala, M. Gottschalk, J. M. Montel, W. Heinrich, An XRD, TEM and Raman study of experimentally annealed natural monazite, Phys. Chem. Miner. 29 (2002) 240-253.

[16] A. M. Seydoux-Guillaume, R. Wirth, A. Deutsch, U. Schärer, Microstructure of 24-1928 Ma concordant monazites; implications for geochronology and nuclear waste deposits, Geochim. Cosmochim. Acta. 68 (2004) 2517-2527.

[17] A. M. Seydoux-Guillaume, J. M. Montel, B. Bingen, V. Bosse, P. de Parseval, J. L. Paquette, E. Janots, R. Wirth, Low-temperature alteration of monazite: Fluid mediated coupled dissolution-precipitation, irradiation damage, and disturbance of the $\mathrm{U}-\mathrm{Pb}$ and Th-Pb chronometers, Chem. Geol. 330-331 (2012) 140-158.

[18] R. C. Ewing, L. Wang, Phosphates as Nuclear Waste Forms, Rev. Mineral. Geochemistry. 48 (2002) 673-699.

[19] L. Nasdala, S. Akhmadaliev, A. Artac, C. Chanmuang N., G. Habler, C. Lenz, Irradiation effects in monazite--(Ce) and zircon: Raman and photoluminescence study of $\mathrm{Au}-$ irradiated FIB foils, Phys. Chem. Miner. 45 (2018) 855-871.

[20] A. M. Seydoux-Guillaume, X. Deschanels, C. Baumier, S. Neumeier, W. J. Weber, Why natural monazite never becomes amorphous: Experimental evidence for alpha selfhealing, Am. Mineral. 103 (2018) 824.

[21] A. Meldrum, L. A. Boatner, R. C. Ewing, A comparison of radiation effects in crystalline $\mathrm{ABO}_{4}$-type phosphates and silicates, Mineral. Mag. 64 (2000) 185-194.

[22] L. Nasdala, M. Wenzel, G. Vavra, G. Irmer, T. Wenzel, B. Kober, Metamictisation of natural zircon: accumulation versus thermal annealing of radioactivity-induced damage, Contrib. to Mineral. Petrol. 141 (2001) 125-144.

[23] W. J. Weber, R. C. Ewing, C. R. A. Catlow, T. D. de la Rubia, L. W. Hobbs, C. Kinoshita, H. Matzke, A. T. Motta, M. Nastasi, E. K. H. Salje, E. R. Vance, S. J. Zinkle, Radiation effects in crystalline ceramics for the immobilization of high-level nuclear waste and plutonium, J. Mater. Res. 13 (1998) 1434-1484.

[24] J. S. Luo, G. K. Liu, Microscopic effects of self-radiation damage in ${ }^{244} \mathrm{Cm}$-doped $\mathrm{LuPO}_{4}$ crystals, J. Mater. Res. 16 (2001) 366-372.

[25] M. R. Rafiuddin, A. P. Grosvenor, Probing the effect of radiation damage on the structure of rare-earth phosphates, J. Alloys Compd. 653 (2015).

[26] V. S. Urusov, A. E. Grechanovsky, N. N. Eremin, Radiation resistance of the xenotime $\mathrm{YPO}_{4}$ from the computer simulation data, Glass Phys. Chem. 38 (2012) 55-62.

[27] C. Lenz, G. Thorogood, R. Aughterson, M. Ionescu, D. J. Gregg, J. Davis, G. R. Lumpkin, The Quantification of Radiation Damage in Orthophosphates Using Confocal $\mu$ Luminescence Spectroscopy of $\mathrm{Nd}^{3+}$, Front. Chem. 7 (2019) 1-13.

[28] T. Degen, M. Sadki, E. Bron, U. König, G. Nénert, The HighScore suite, Powder Diffr. 29 (2014) S13-S18. 
[29] L. W. Hobbs, Topology and geometry in the irradiation-induced amorphization of insulators, Nucl. Instruments Methods Phys. Res. Sect. B Beam Interact. with Mater. Atoms. 91 (1994) 30-42.

[30] A. Debelle, M. Backman, L. Thomé, K. Nordlund, F. Djurabekova, W. J. Weber, I. Monnet, O. H. Pakarinen, F. Garrido, F. Paumier, Swift heavy ion induced recrystallization in cubic silicon carbide: New insights from designed experiments and MD simulations, Nucl. Instruments Methods Phys. Res. Sect. B Beam Interact. with Mater. Atoms. 326 (2014) 326-331.

[31] S. J. Zinkle, Microstructure of ion irradiated ceramic insulators, Nucl. Instruments Methods Phys. Res. Sect. B Beam Interact. with Mater. Atoms. 91 (1994) 234-246.

[32] S. J. Zinkle, Fundamental radiation effects parameters in metals and ceramics, Radiat. Eff. Defects Solids. 148 (1999) 447-477.

[33] S. J. Zinkle, Effect of irradiation spectrum on the microstructural evolution in ceramic insulators, J. Nucl. Mater. 219 (1995) 113-127.

[34] K. Yasuda, C. Kinoshita, Electron-beam induced dissociation of dislocation loops in magnesia-alumina ceramics, Nucl. Instruments Methods Phys. Res. Sect. B Beam Interact. with Mater. Atoms. 191 (2002) 559-564.

[35] W. J. Weber, D. M. Duffy, L. Thomé, Y. Zhang, The role of electronic energy loss in ion beam modification of materials, Curr. Opin. Solid State Mater. Sci. 19 (2015) 1-11.

[36] F. C. Hawthorne, L. A. Groat, M. Raudsepp, N. A. Ball, M. Kimata, F. D. Spike, R. G. Gaba, N. M. Halden, G. R. Lumpkin, R. C. Ewing, R. B. Greegor, F. W. Lytle, T. S. Ercit, G. R. Rossman, F. J. Wicks, R. A. Ramik, B. L. Sherriff, M. E. Fleet, C. McCammon, Alpha-decay damage in titanite, Am. Mineral. 76 (1991) 370-396.

[37] G. R. Lumpkin, R. C. Ewing, Alpha-decay damage in minerals of the pyrochlore group, Phys. Chem. Miner. 16 (1988) 2-20.

[38] X. Deschanels, A. M. Seydoux-Guillaume, V. Magnin, A. Mesbah, M. Tribet, M. P. Moloney, Y. Serruys, S. Peuget, Swelling induced by alpha decay in monazite and zirconolite ceramics: A XRD and TEM comparative study, J. Nucl. Mater. 448 (2014) 184-194.

[39] K. Momma, F. Izumi, VESTA: a three-dimensional visualization system for electronic and structural analysis, J. Appl. Crystallogr. 41 (2008) 653-658. 
Tables

Table 1: Electronic and Nuclear Stopping Powers for $\mathrm{ErPO}_{4}$

\begin{tabular}{cccc}
\hline Ion-beam & $\begin{array}{c}\text { Electronic Stopping } \\
\text { Power }(\mathbf{d E} / \mathbf{d x}) \mathbf{e}(\mathbf{e V} / \mathbf{n m})\end{array}$ & $\begin{array}{c}\text { Nuclear Stopping } \\
\text { Power }(\mathbf{d E} / \mathbf{d x})_{\mathbf{n}}(\mathbf{e V} / \mathbf{n m})\end{array}$ & ENSP \\
\hline $\mathrm{Au}^{2+}(1.5 \mathrm{MeV})$ & 1725 & 4034 & 0.4276 \\
$\mathrm{He}^{+}(160 \mathrm{keV})$ & 279 & 2.442 & 114.2 \\
$\left(\mathrm{Au}^{2+}+\mathrm{He}^{+}\right)^{*}$ & 2004 & 4036 & 0.4965
\end{tabular}

${ }^{*}$ The electronic and nuclear stopping factors of dual ion-beam $\left(\mathrm{Au}^{2+}+\mathrm{He}^{+}\right)$were obtained through summation of electronic and nuclear stopping powers of their respective single ion -beams 
Table 2: Sequential ion-irradiation of $\mathrm{ErPO}_{4}$

\begin{tabular}{|c|c|c|c|c|c|c|}
\hline Steps & $\begin{array}{c}\text { Flux } \\
\left(\text { ions } / \mathbf{c m}^{2} / \mathbf{s}\right)\end{array}$ & $\begin{array}{l}\text { Temperature of } \\
\text { TEM foil }\end{array}$ & $\begin{array}{c}\mathrm{Au}^{2+} \text { fluence } \\
\left(\text { ions } / \mathbf{c m}^{2}\right)\end{array}$ & $\begin{array}{l}\mathrm{He}^{+} \text {fluence } \\
(\text { ions/cm }\end{array}$ & $\begin{array}{c}\text { Eelectronic } \\
\left({\left.\mathrm{keV} / \mathrm{cm}^{3}\right)}^{3}\right)\end{array}$ & 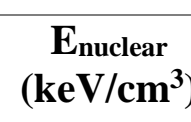 \\
\hline 1 & $\mathrm{Au}^{2+}: 2.0 \times 10^{10}$ & $25^{\circ} \mathrm{C}$ & $1.0 \times 10^{13}$ & & $2.3 \times 10^{20}$ & $5.3 \times 10^{20}$ \\
\hline 2 & & & $5.0 \times 10^{13}$ & & $1.0 \times 10^{21}$ & $2.3 \times 10^{21}$ \\
\hline 3 & & & $1.0 \times 10^{14}$ & & $2.1 \times 10^{21}$ & $4.7 \times 10^{21}$ \\
\hline 4 & & & $2.0 \times 10^{14}$ & & $4.1 \times 10^{21}$ & $9.4 \times 10^{21}$ \\
\hline 5 & $\mathrm{He}^{+}: 1.0 \times 10^{12}$ & $25^{\circ} \mathrm{C}$ & & $3.0 \times 10^{13}$ & $1.2 \times 10^{20}$ & $1.0 \times 10^{18}$ \\
\hline 6 & & & & $5.0 \times 10^{14}$ & $1.7 \times 10^{21}$ & $1.5 \times 10^{19}$ \\
\hline 7 & & & & $1.0 \times 10^{15}$ & $3.5 \times 10^{21}$ & $3.0 \times 10^{19}$ \\
\hline 8 & & & & $5.0 \times 10^{15}$ & $1.7 \times 10^{22}$ & $1.5 \times 10^{20}$ \\
\hline 9 & & & & $1.0 \times 10^{16}$ & $3.4 \times 10^{22}$ & $3.0 \times 10^{20}$ \\
\hline 10 & $\mathrm{He}^{+}: 3.0 \times 10^{12}$ & $28^{\circ} \mathrm{C}$ & & $3.0 \times 10^{16}$ & $1.0 \times 10^{23}$ & $8.9 \times 10^{20}$ \\
\hline 11 & & & & $4.0 \times 10^{16}$ & $1.4 \times 10^{23}$ & $1.2 \times 10^{21}$ \\
\hline 12 & & & & $5.0 \times 10^{16}$ & $1.7 \times 10^{23}$ & $1.5 \times 10^{21}$ \\
\hline 13 & $\mathrm{He}^{+}: 1.3 \times 10^{13}$ & $55^{\circ} \mathrm{C}$ & & $7.0 \times 10^{16}$ & $2.4 \times 10^{23}$ & $2.1 \times 10^{21}$ \\
\hline 14 & & & & $1.0 \times 10^{17}$ & $3.4 \times 10^{23}$ & $3.0 \times 10^{21}$ \\
\hline
\end{tabular}


Table 3: Simultaneous ion-irradiation of $\mathrm{ErPO}_{4}$

\begin{tabular}{|c|c|c|c|c|c|c|c|}
\hline Steps & $\begin{array}{c}\text { Flux } \\
\left(\text { ions } / \mathrm{cm}^{2} / \mathbf{s}\right)\end{array}$ & $\begin{array}{l}\text { Temperature } \\
\text { of TEM foil }\end{array}$ & $\begin{array}{c}\mathrm{Au}^{2+} \text { fluence } \\
\left(\text { ions/cm } / \mathbf{c m}^{2}\right)\end{array}$ & 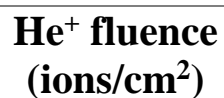 & 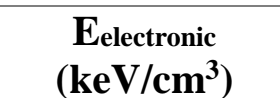 & $\begin{array}{c}\text { Enuclear } \\
\left({\left.\mathrm{keV} / \mathrm{cm}^{3}\right)}^{3}\right.\end{array}$ & $\begin{array}{c}\text { Eelectronid } \\
\text { Enuclear }\end{array}$ \\
\hline \multirow[t]{2}{*}{1} & $\mathrm{Au}^{2+}: 2.0 \times 10^{10}$ & $28^{\circ} \mathrm{C}$ & $1.0 \times 10^{13}$ & $1.40 \times 10^{15}$ & $2.3 \times 10^{20}(\mathrm{Au})$ & $5.3 \times 10^{20}(\mathrm{Au})$ & $\sim 9$ \\
\hline & $\mathrm{He}^{+}: 3.0 \times 10^{12}$ & & & & $4.8 \times 10^{21}(\mathrm{He})$ & $4.2 \times 10^{19}(\mathrm{He})$ & \\
\hline \multirow[t]{2}{*}{2} & & & $5.0 \times 10^{13}$ & $7.37 \times 10^{15}$ & $1.0 \times 10^{21}(\mathrm{Au})$ & $2.3 \times 10^{21}(\mathrm{Au})$ & $\sim 10$ \\
\hline & & & & & $2.5 \times 10^{22}(\mathrm{He})$ & $2.2 \times 10^{20}(\mathrm{He})$ & \\
\hline \multirow[t]{2}{*}{3} & & & $1.0 \times 10^{14}$ & $1.50 \times 10^{16}$ & $2.1 \times 10^{21}(\mathrm{Au})$ & $4.7 \times 10^{21}(\mathrm{Au})$ & $\sim 10$ \\
\hline & & & & & $5.1 \times 10^{22}(\mathrm{He})$ & $4.5 \times 10^{20}(\mathrm{He})$ & \\
\hline \multirow[t]{2}{*}{1} & $\mathrm{Au}^{2+}: 2.0 \times 10^{10}$ & $43^{\circ} \mathrm{C}$ & $1.0 \times 10^{13}$ & $2.83 \times 10^{15}$ & $2.3 \times 10^{20}(\mathrm{Au})$ & $5.3 \times 10^{20}(\mathrm{Au})$ & $\sim 16$ \\
\hline & $\mathrm{He}^{+}: 5.0 \times 10^{12}$ & & & & $9.7 \times 10^{21}(\mathrm{He})$ & $8.4 \times 10^{19}(\mathrm{He})$ & \\
\hline \multirow[t]{2}{*}{2} & $\mathrm{Au}^{2+}: 2.0 \times 10^{10}$ & & $5.0 \times 10^{13}$ & $1.35 \times 10^{16}$ & $1.0 \times 10^{21}(\mathrm{Au})$ & $2.3 \times 10^{21}(\mathrm{Au})$ & $\sim 17$ \\
\hline & $\mathrm{He}^{+}: 5.4 \times 10^{12}$ & & & & $4.6 \times 10^{22}(\mathrm{He})$ & $4.0 \times 10^{20}(\mathrm{He})$ & \\
\hline \multirow[t]{2}{*}{3} & $\mathrm{Au}^{2+}: 2.0 \times 10^{10}$ & & $1.0 \times 10^{14}$ & $2.78 \times 10^{16}$ & $2.1 \times 10^{21}(\mathrm{Au})$ & $4.7 \times 10^{21}(\mathrm{Au})$ & $\sim 18$ \\
\hline & $\mathrm{He}^{+}: 5.6 \times 10^{12}$ & & & & $9.5 \times 10^{22}(\mathrm{He})$ & $8.3 \times 10^{20}(\mathrm{He})$ & \\
\hline
\end{tabular}


Table 4: Simultaneous ion-irradiation of $\mathrm{ErPO}_{4}$

\begin{tabular}{|c|c|c|c|c|c|c|c|}
\hline Steps & $\begin{array}{c}\text { Flux } \\
(\text { ions/cm²/s) }\end{array}$ & $\begin{array}{c}\text { Temperature } \\
\text { of TEM foil }\end{array}$ & $\begin{array}{c}A u^{2+} \text { fluence } \\
(\text { ions/cm } \\
\end{array}$ & $\begin{array}{c}\mathrm{He}^{+} \text {fluence } \\
(\text { ions/cm²) }\end{array}$ & $\begin{array}{c}\text { Eelectronic } \\
\left(\mathbf{k e V} / \mathrm{cm}^{3}\right)\end{array}$ & $\begin{array}{c}\begin{array}{c}\text { Enuclear } \\
\left(\mathrm{keV} / \mathrm{cm}^{3}\right)\end{array} \\
\end{array}$ & $\begin{array}{c}\text { Eelectronic } \\
\text { Enuclear }\end{array}$ \\
\hline \multirow[t]{2}{*}{1} & $\mathrm{Au}^{2+}: 2.0 \times 10^{10}$ & $56^{\circ} \mathrm{C}$ & $1.0 \times 10^{13}$ & $7.57 \times 10^{15}$ & $2.3 \times 10^{20}(\mathrm{Au})$ & $5.3 \times 10^{20}(\mathrm{Au})$ & 37 \\
\hline & $\mathrm{He}^{+}: 1.4 \times 10^{13}$ & & & & $2.6 \times 10^{22}(\mathrm{He})$ & $2.3 \times 10^{20}(\mathrm{He})$ & \\
\hline \multirow[t]{2}{*}{2} & & & $5.0 \times 10^{13}$ & $3.69 \times 10^{16}$ & $1.0 \times 10^{21}(\mathrm{Au})$ & $2.3 \times 10^{21}(\mathrm{Au})$ & 39 \\
\hline & & & & & $1.3 \times 10^{23}(\mathrm{He})$ & $1.1 \times 10^{21}(\mathrm{He})$ & \\
\hline \multirow[t]{2}{*}{3} & & & $1.0 \times 10^{14}$ & $7.12 \times 10^{16}$ & $2.1 \times 10^{21}(\mathrm{Au})$ & $4.7 \times 10^{21}(\mathrm{Au})$ & 36 \\
\hline & & & & & $2.4 \times 10^{23}(\mathrm{He})$ & $2.1 \times 10^{21}(\mathrm{He})$ & \\
\hline \multirow[t]{2}{*}{4} & & & $1.5 \times 10^{14}$ & $1.09 \times 10^{17}$ & $3.1 \times 10^{21}(\mathrm{Au})$ & $7.0 \times 10^{21}(\mathrm{Au})$ & 37 \\
\hline & & & & & $3.7 \times 10^{23}(\mathrm{He})$ & $3.2 \times 10^{21}(\mathrm{He})$ & \\
\hline \multirow[t]{2}{*}{5} & & & $2.0 \times 10^{14}$ & $1.42 \times 10^{17}$ & $4.1 \times 10^{21}(\mathrm{Au})$ & $9.3 \times 10^{21}(\mathrm{Au})$ & 36 \\
\hline & & & & & $4.8 \times 10^{23}(\mathrm{He})$ & $4.2 \times 10^{21}(\mathrm{He})$ & \\
\hline \multirow[t]{2}{*}{1} & $\mathrm{Au}^{2+}: 2.0 \times 10^{10}$ & $100^{\circ} \mathrm{C}$ & $1.0 \times 10^{13}$ & $1.52 \times 10^{16}$ & $2.3 \times 10^{20}(\mathrm{Au})$ & $5.3 \times 10^{20}(\mathrm{Au})$ & 57 \\
\hline & $\mathrm{He}^{+}: 2.9 \times 10^{13}$ & & & & $5.2 \times 10^{22}(\mathrm{He})$ & $4.5 \times 10^{20}(\mathrm{He})$ & \\
\hline \multirow[t]{2}{*}{2} & & & $5.0 \times 10^{13}$ & $7.12 \times 10^{16}$ & $1.0 \times 10^{21}(\mathrm{Au})$ & $2.3 \times 10^{21}(\mathrm{Au})$ & 55 \\
\hline & & & & & $2.4 \times 10^{23}(\mathrm{He})$ & $2.1 \times 10^{21}(\mathrm{He})$ & \\
\hline \multirow[t]{2}{*}{3} & & & $1.0 \times 10^{14}$ & $1.41 \times 10^{17}$ & $2.1 \times 10^{21}(\mathrm{Au})$ & $4.7 \times 10^{21}(\mathrm{Au})$ & 54 \\
\hline & & & & & $4.8 \times 10^{23}(\mathrm{He})$ & $4.2 \times 10^{21}(\mathrm{He})$ & \\
\hline \multirow[t]{2}{*}{4} & & & $2.0 \times 10^{14}$ & $2.87 \times 10^{17}$ & $4.1 \times 10^{21}(\mathrm{Au})$ & $9.3 \times 10^{21}(\mathrm{Au})$ & 55 \\
\hline & & & & & $9.8 \times 10^{23}(\mathrm{He})$ & $8.5 \times 10^{21}(\mathrm{He})$ & \\
\hline
\end{tabular}


Table 5: Electron beam irradiation of amorphous $\mathrm{ErPO}_{4}$

\begin{tabular}{|c|c|c|c|c|c|}
\hline Steps & $\begin{array}{c}\mathrm{Au}^{2+} \text { ion } \\
\text { fluence } \\
\left(\text { ions } / \mathrm{cm}^{2}\right)\end{array}$ & $\begin{array}{l}\text { Temperature } \\
\text { of TEM foil } \\
\left({ }^{\circ} \mathrm{C}\right)\end{array}$ & $\begin{array}{l}\text { Electron flux } \\
\left(\mathrm{e}^{\left.-/ \mathbf{n m}^{2} / \mathbf{s}\right)}\right.\end{array}$ & $\begin{array}{l}\text { Electron } \\
\text { exposure } \\
\text { time (s) }\end{array}$ & $\begin{array}{c}\text { TEM observation } \\
\text { conditions }\end{array}$ \\
\hline 1 & $1.0 \times 10^{14}$ & 26 & 170 & - & - \\
\hline 2 & & & 270 & $\mathrm{t} \leq 90 \mathrm{~min}$ & $\begin{array}{l}\text { Cond. } 3 \text {, Obj. } 2, \alpha \\
=-41, \beta=22,5, \\
\text { Spot size } 3, \text { Mag. } \\
\text { SA } 25500 x- \\
29000 x\end{array}$ \\
\hline 3 & & & 270 & $90 \leq \mathrm{t} \leq 165$ & $\begin{array}{l}\text { Cond. } 3 \text {, Obj. } 2, \alpha \\
=-41, \beta=22,5, \\
\text { Spot size } 1, \text { Mag. } \\
\text { SA } 25500 x- \\
29000 x\end{array}$ \\
\hline 3 & & & 1130 & $167 \leq \mathrm{t} \leq 195$ & $\begin{array}{l}\text { Cond. } 3 \text {, Obj. } 2, \alpha \\
=-41, \beta=22,5, \\
\text { Spot size } 1, \text { Mag. } \\
\text { SA } 25500 x- \\
29000 x\end{array}$ \\
\hline 4 & & & 5040 & $200 \leq \mathrm{t} \leq 260$ & $\begin{array}{l}\text { Cond. } 3 \text {, Obj. } 2, \alpha \\
=-41, \beta=22,5 \text {, } \\
\text { Spot size } 1, \text { Mag. } \\
\text { SA } 55000 x- \\
62000 x\end{array}$ \\
\hline
\end{tabular}


Table 6: Lattice constants of xenotime-type $\mathrm{ErPO}_{4}$

Sample Lattice constants

$$
\begin{array}{rl}
\mathrm{ErPO}_{4} & \mathrm{a}=6.8613(1) \AA \\
\mathrm{c} & =6.0097(1) \AA
\end{array}
$$

Volume $=282.92 \AA^{3}$ 
Table 7: Interplanar distance $\mathrm{d}_{\mathrm{hkl}}$ values of electron beam induced recrystallized samples

\begin{tabular}{|c|c|c|c|}
\hline Diffraction spots & (h k l) & dhkl $_{\text {- Experimental }(\AA)}$ & $\mathbf{d}_{\text {hkl }}-$ Theoretical $(\AA)$ \\
\hline 1 & $\left(\begin{array}{lll}1 & 0 & 1\end{array}\right)$ & 4.5523 & 4.5379 \\
\hline 2 & $\left(\begin{array}{lll}2 & 0 & 0\end{array}\right)$ & 3.4504 & 3.4474 \\
\hline 3 & $\left(\begin{array}{lll}1 & 1 & 2\end{array}\right)$ & 2.6044 & 2.5635 \\
\hline
\end{tabular}




\section{Figure captions}

Figure 1: Crystal structure of xenotime-type $\mathrm{YPO}_{4}$ (Space group: I41/amd). The crystal structures were generated using the VESTA software.[39]

Figure 2: Powder $\mathrm{XRD}$ pattern of the xenotime-type $\mathrm{ErPO}_{4}$ pellet sintered at $1600^{\circ} \mathrm{C}$ in air.

Figure 3: BF-TEM image of thin foil of pristine $\mathrm{ErPO}_{4}$ samples. The SAED pattern of pristine $\mathrm{ErPO}_{4}$ is shown in the inset.

Figure 4: BF-TEM images and the corresponding SAED patterns (inset) of $\mathrm{ErPO}_{4} \mathrm{samples}$ irradiated sequentially with $\mathrm{Au}^{2+}$ ions to ion-fluences of $1 \times 10^{13}$ ions $/ \mathrm{cm}^{2}(\mathrm{~A}), 5 \times 10^{13}$ ions $/ \mathrm{cm}^{2}$ (B), and $2 \times 10^{14}$ ions $/ \mathrm{cm}^{2}(\mathrm{C})$. The BF-TEM image and the corresponding SAED pattern (inset) of amorphous $\mathrm{ErPO}_{4}$ irradiated with $\mathrm{He}^{+}$ions to an ion-fluence of $1 \times 10^{17}$ ions $/ \mathrm{cm}^{2}$ (D).

Figure 5: BF-TEM images and corresponding SAED pattern (inset) of $\mathrm{ErPO}_{4}$ sample obtained before irradiation (A). BF-TEM images and corresponding SAED patterns (inset) of $\mathrm{ErPO}_{4}$ irradiated simultaneously with $\mathrm{Au}^{2+}$ and $\mathrm{He}^{+}$ions $\left(\mathrm{E}_{\text {electronic }} / \mathrm{E}_{\text {nuclear }}=10\right)$ to higher ion-fluences of $\mathrm{Au}^{2+}: 1 \times 10^{13}$ ions $/ \mathrm{cm}^{2} ; \mathrm{He}^{+}: 1.40 \times 10^{15}$ ions $/ \mathrm{cm}^{2}(\mathrm{~B}), \mathrm{Au}^{2+}: 5 \times 10^{13}$ ions $/ \mathrm{cm}^{2} ; \mathrm{He}^{+}: 7.37 \times 10^{15}$ ions $/ \mathrm{cm}^{2}(\mathrm{C})$, and $\mathrm{Au}^{2+}: 1 \times 10^{14}$ ions $/ \mathrm{cm}^{2} ; \mathrm{He}^{+}: 1.5 \times 10^{16}$ ions $/ \mathrm{cm}^{2}(\mathrm{D})$.

Figure 6: BF-TEM images and corresponding SAED pattern (inset) of $\mathrm{ErPO}_{4}$ sample obtained before (A) and after irradiation $(\mathrm{B}-\mathrm{E})$ are presented. BF-TEM images of $\mathrm{ErPO}_{4}$ irradiated simultaneously with $\mathrm{Au}^{2+}$ and $\mathrm{He}^{+}$ions $\left(\mathrm{E}_{\text {electronic }} / \mathrm{E}_{\text {nuclear }}=17-18\right)$ to an ion-fluence of $\mathrm{Au}^{2+}: 1 \times$ $10^{13}$ ions $/ \mathrm{cm}^{2} ; \mathrm{He}^{+}: 2.83 \times 10^{15}$ ions $/ \mathrm{cm}^{2}(\mathrm{~B})$. The image $(\mathrm{C})$ which was obtained upon magnification of the region represented by the white box in (B) clearly reveals the presence of mottled diffraction contrast. The BF-TEM images and the corresponding SAED patterns (inset) of $\mathrm{ErPO}_{4}$ irradiated simultaneously with $\mathrm{Au}^{2+}$ and $\mathrm{He}^{+}$ions to higher ion-fluences of $\mathrm{Au}^{2+}: 5 \times 10^{13}$ 
ions $/ \mathrm{cm}^{2} ; \mathrm{He}^{+}: 1.35 \times 10^{16}$ ions $/ \mathrm{cm}^{2}(\mathrm{D})$ and $\mathrm{Au}^{2+}: 1 \times 10^{14}$ ions $/ \mathrm{cm}^{2} ; \mathrm{He}^{+}: 2.78 \times 10^{16}$ ions $/ \mathrm{cm}^{2}$ (E). The presence of two diffraction spots in the SAED pattern of (D) are indicated by two red arrows. Global view of the $\mathrm{ErPO}_{4}$ lamella after dual ion-beam radiation (F).

Figure 7: BF-TEM images and corresponding SAED pattern (inset) of $\mathrm{ErPO}_{4}$ sample obtained before (A) and after irradiation (B - F). BF-TEM images and corresponding SAED pattern (inset) of $\mathrm{ErPO}_{4}$ irradiated simultaneously with $\mathrm{Au}^{2+}$ and $\mathrm{He}^{+}$ions $\left(\mathrm{E}_{\text {electronic }} / \mathrm{E}_{\text {nuclear }}=36-39\right)$ to ionfluences of $\mathrm{Au}^{2+}: 1 \times 10^{13}$ ions $/ \mathrm{cm}^{2} ; \mathrm{He}^{+}: 7.57 \times 10^{15} \mathrm{ions} / \mathrm{cm}^{2}(\mathrm{~B}), \mathrm{Au}^{2+}: 5 \times 10^{13}$ ions $/ \mathrm{cm}^{2} ; \mathrm{He}^{+}$: $3.69 \times 10^{16}$ ions $/ \mathrm{cm}^{2}(\mathrm{C}), \mathrm{Au}^{2+}: 1 \times 10^{14} \mathrm{ions} / \mathrm{cm}^{2} ; \mathrm{He}^{+}: 7.12 \times 10^{16} \mathrm{ions} / \mathrm{cm}^{2}(\mathrm{D}), \mathrm{Au}^{2+}: 1.50 \times$ $10^{14}$ ions $/ \mathrm{cm}^{2} ; \mathrm{He}^{+}: 1.09 \times 10^{17}$ ions $/ \mathrm{cm}^{2}(\mathrm{E})$, and $\mathrm{Au}^{2+}: 2 \times 10^{14}$ ions $/ \mathrm{cm}^{2} ; \mathrm{He}^{+}: 1.42 \times 10^{17}$ ions $/ \mathrm{cm}^{2}(\mathrm{~F})$.

Figure 8: BF-TEM images and corresponding SAED pattern (inset) of $\mathrm{ErPO}_{4}$ sample obtained before (A) and after irradiation (B - F). BF-TEM images and corresponding SAED pattern (inset) of $\mathrm{ErPO}_{4}$ irradiated simultaneously with $\mathrm{Au}^{2+}$ and $\mathrm{He}^{+}$ions $\left(\mathrm{E}_{\text {electronic/ }} / \mathrm{E}_{\text {nuclear }}=54-57\right)$ to ionfluences of $\mathrm{Au}^{2+}: 1 \times 10^{13}$ ions $/ \mathrm{cm}^{2} ; \mathrm{He}^{+}: 1.52 \times 10^{16}$ ions $/ \mathrm{cm}^{2}(\mathrm{~B}), \mathrm{Au}^{2+}: 5 \times 10^{13}$ ions $/ \mathrm{cm}^{2} ; \mathrm{He}^{+}$: $7.12 \times 10^{16}$ ions $/ \mathrm{cm}^{2}(\mathrm{D}), \mathrm{Au}^{2+}: 1 \times 10^{14}$ ions $/ \mathrm{cm}^{2} ; \mathrm{He}^{+}: 1.41 \times 10^{17}$ ions $/ \mathrm{cm}^{2}(\mathrm{~F})$, and $\mathrm{Au}^{2+}: 2 \times$ $10^{14}$ ions $/ \mathrm{cm}^{2} ; \mathrm{He}^{+}: 2.87 \times 10^{17}$ ions $/ \mathrm{cm}^{2}(\mathrm{H})$. The images shown in $(\mathrm{C}),(\mathrm{E}),(\mathrm{G})$, and (I) were obtained upon magnification of regions represented by white boxes in (B), (D), (F), and (H), respectively. The mottled diffraction contrasts due to ion-irradiation were clearly observed in (C), (E), (G), and (I).

Figure 9: Electron-beam induced recrystallization of amorphous $\mathrm{ErPO}_{4}$. BF-TEM images and corresponding SAED patterns obtained before (A) and after (B) $\mathrm{Au}^{2+}$ ion-irradiation. BF-TEM images of amorphous $\mathrm{ErPO}_{4}$ after exposure to the electron beam for a duration of 10 minutes $(\mathrm{C})$, 120 minutes (D), 150 minutes (E), 200 minutes (F), 215 minutes (G), 230 minutes $(H)$, and 260 
minutes (I). The regions indicated by circles and arrows in (D) and (E) indicate the first appearance of recrystallized nuclei.

Figure 10: SAED pattern of the electron beam induced recrystallized samples. The $\mathrm{d}_{\mathrm{hkl}}$ values were obtained from the labelled diffraction spots $(1,2,3)$ and compared with the $\mathrm{d}_{\mathrm{hkl}}$ values reported by $\mathrm{Ni}$ et al.[7]

Figure 10: Global BF-TEM image of the $\mathrm{Au}^{2+}$ ion-irradiated $\mathrm{ErPO}_{4}$ lamella after electron irradiation experiment. The region enclosed within the circle indicates the area of the lamella exposed to the electron beam. Electron beam induced recrystallization of amorphous $\mathrm{ErPO}_{4}$ was observed in the region exposed to electron beam. The region of the lamella not exposed to the electron beam is amorphous.

Figure 11: Comparison of the dual-ion beam radiation response of monazite and xenotime structures. Logarithmic plot of electronic energy ( $\left.E_{\text {electronic }}\right)$ versus nuclear energy $\left(E_{\text {nuclear }}\right)$ is presented. The Eelectronic and $E_{\text {nuclear }}$ values for the monazite structure was obtained from the study by Seydoux-Guillaume et al.[20] 
Figure 1

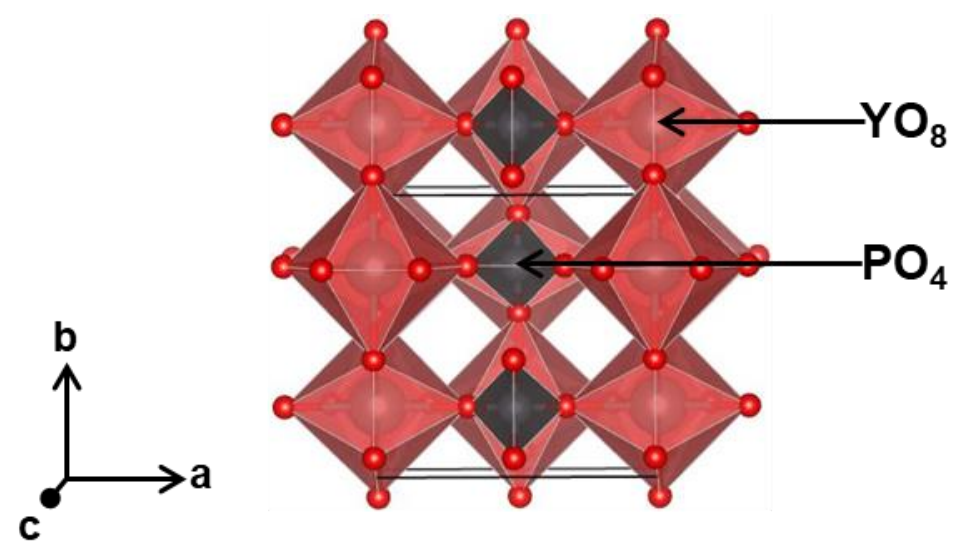


Figure 2

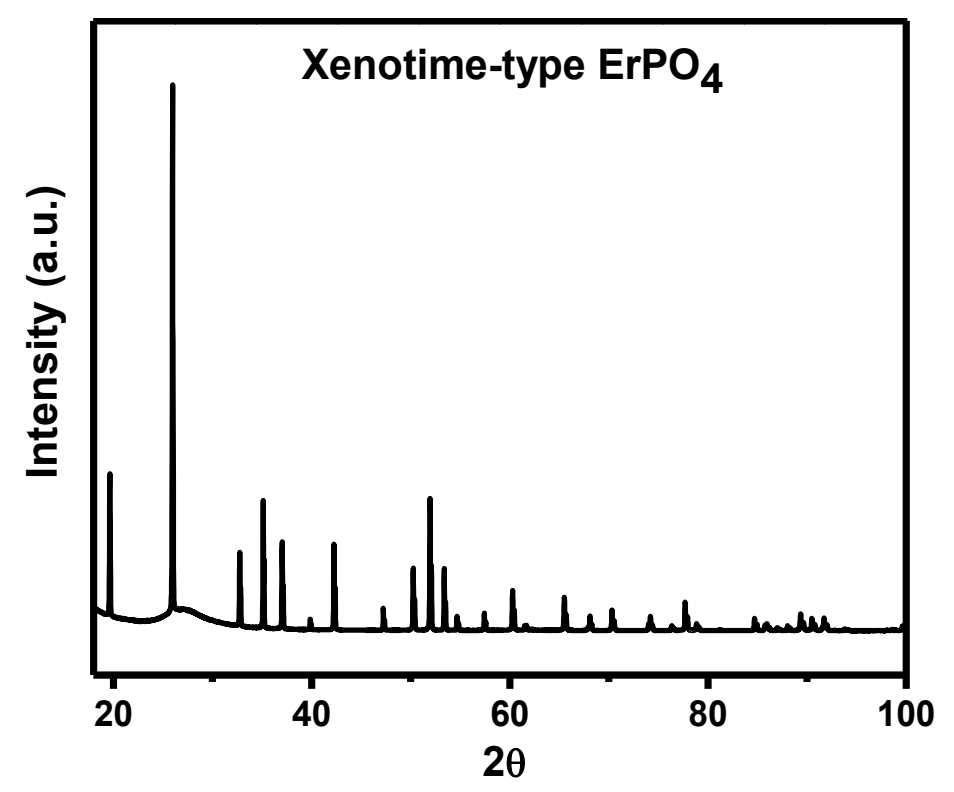


Figure 3

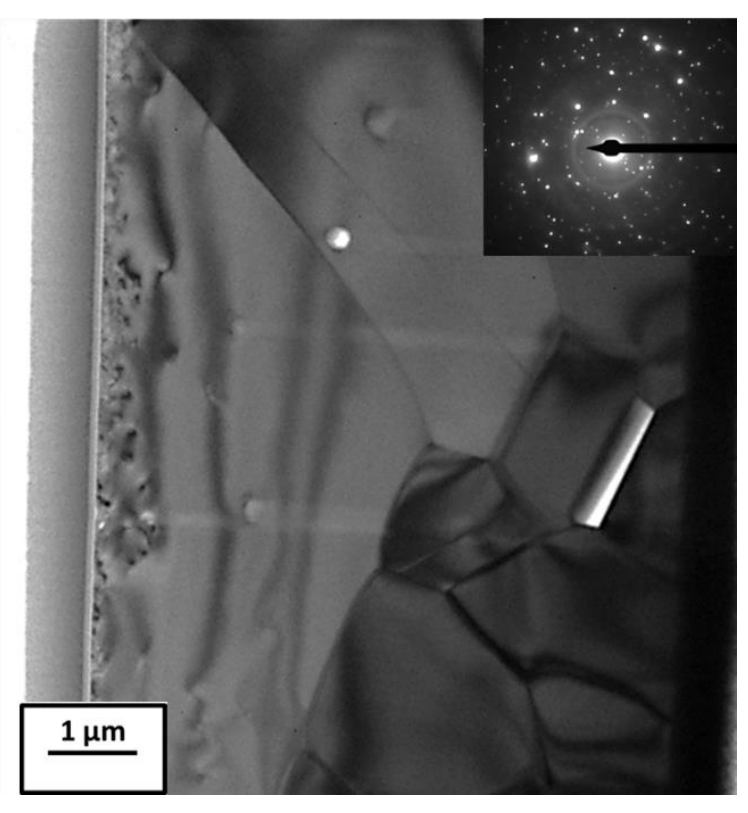


Figure 4

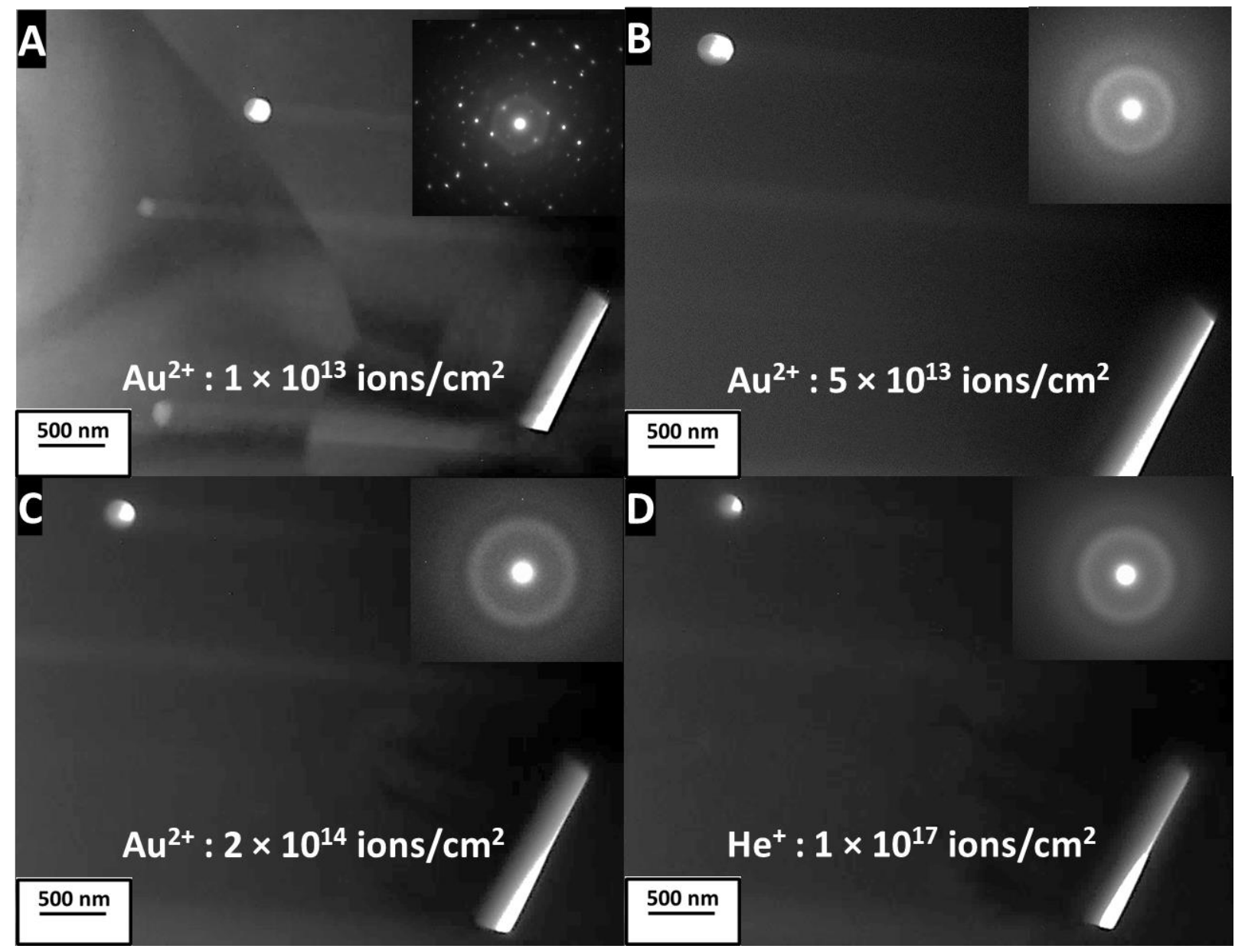


Figure 5

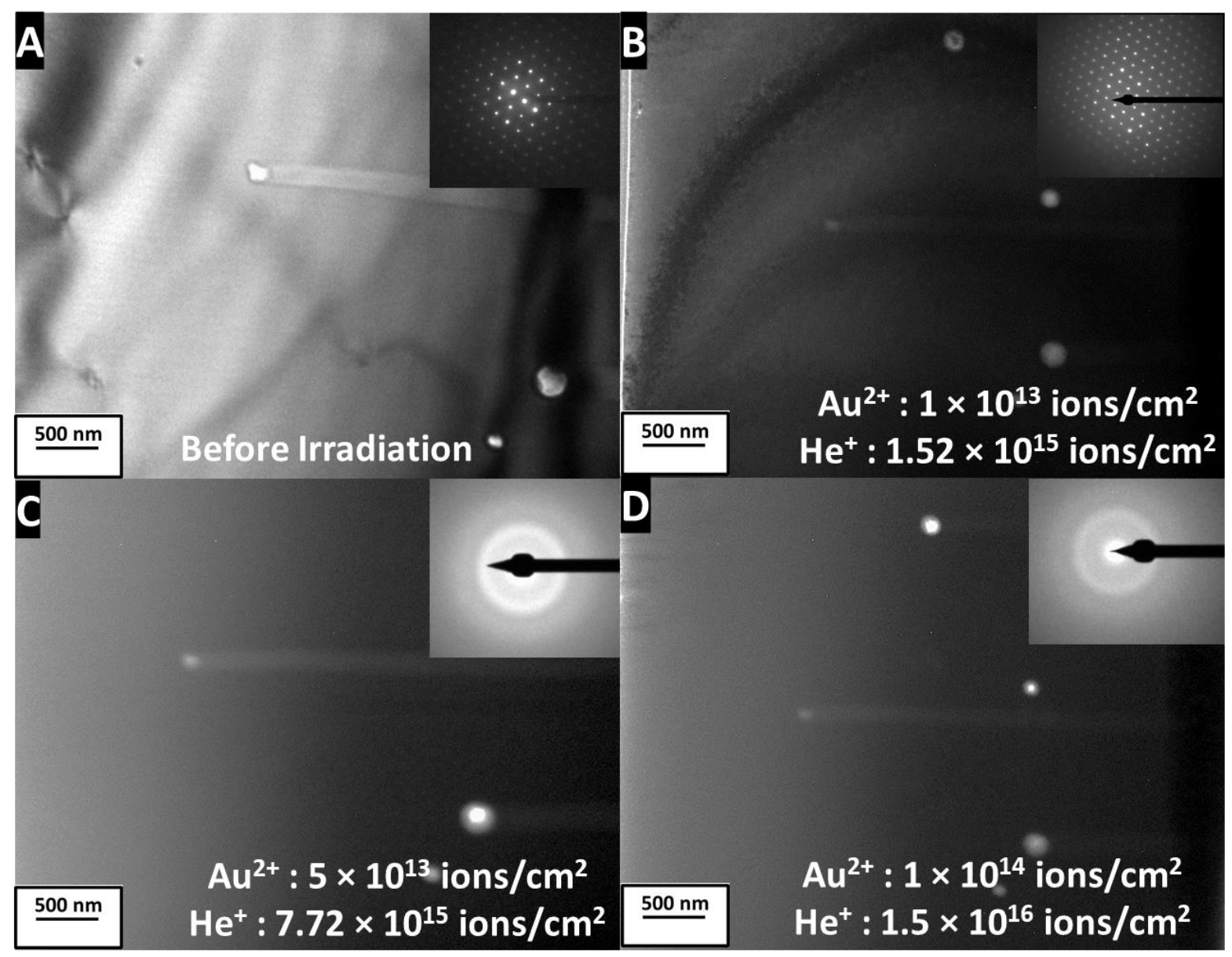


Figure 6

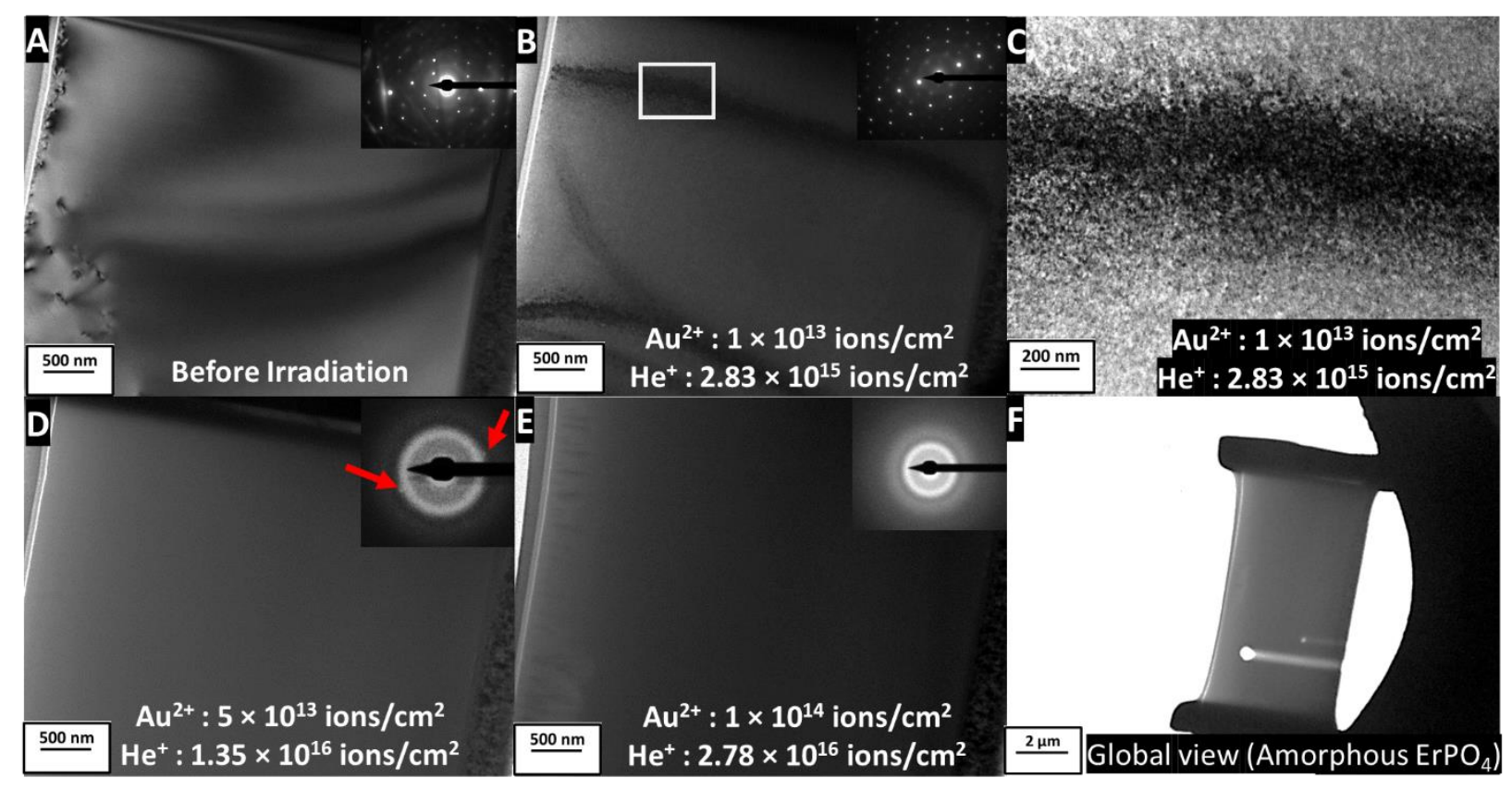


Figure 7

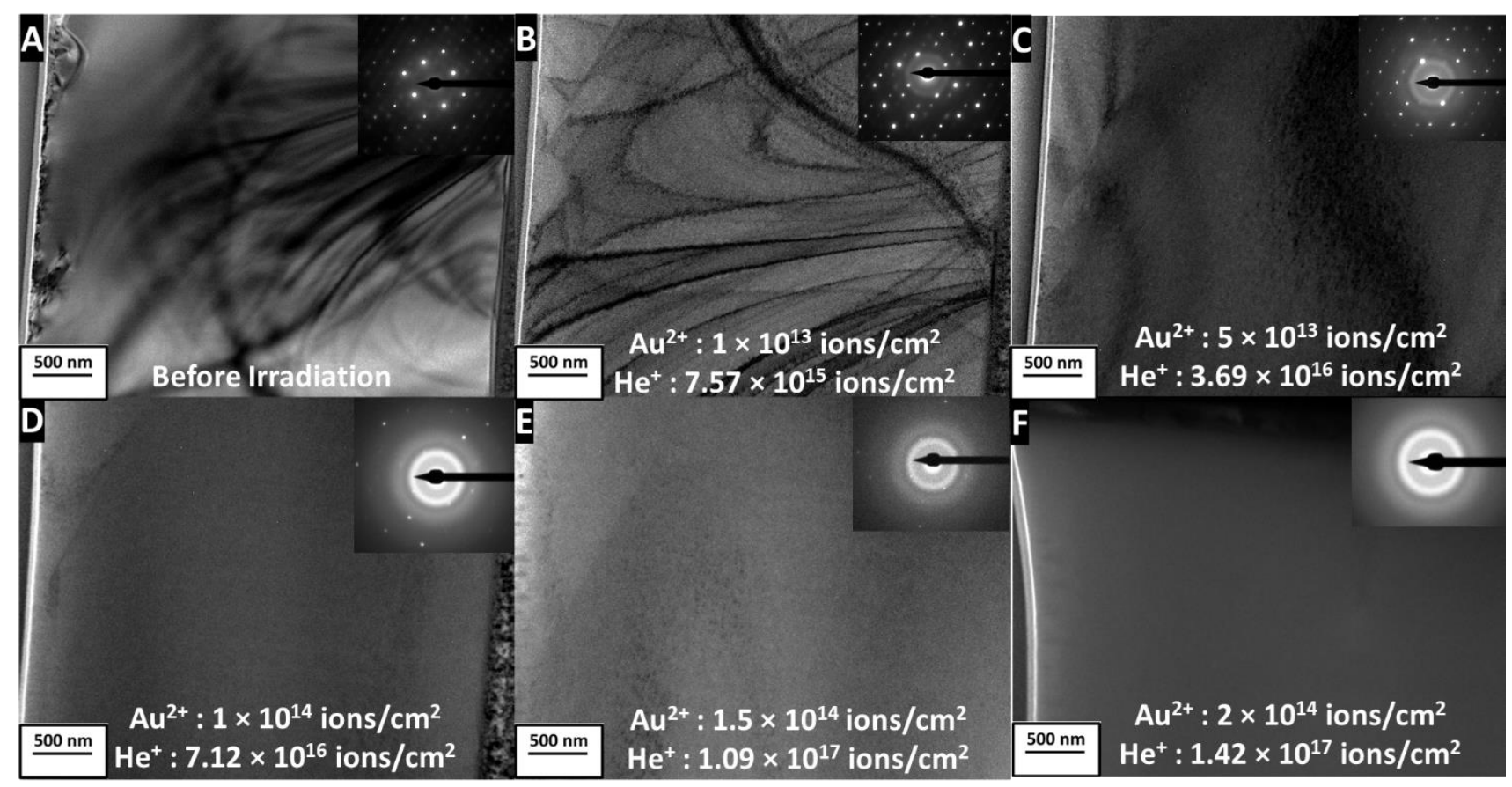


Figure 8

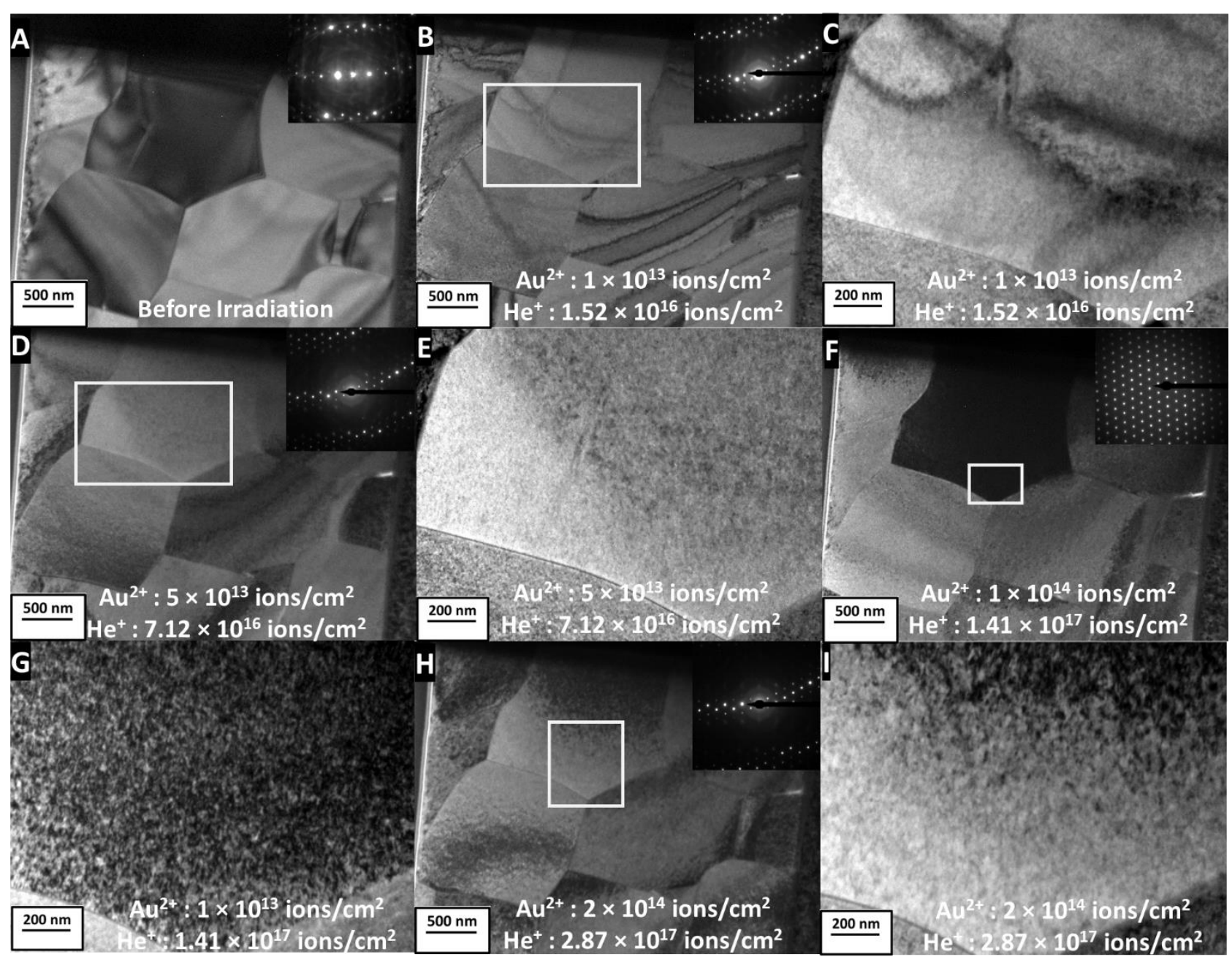


Figure 9

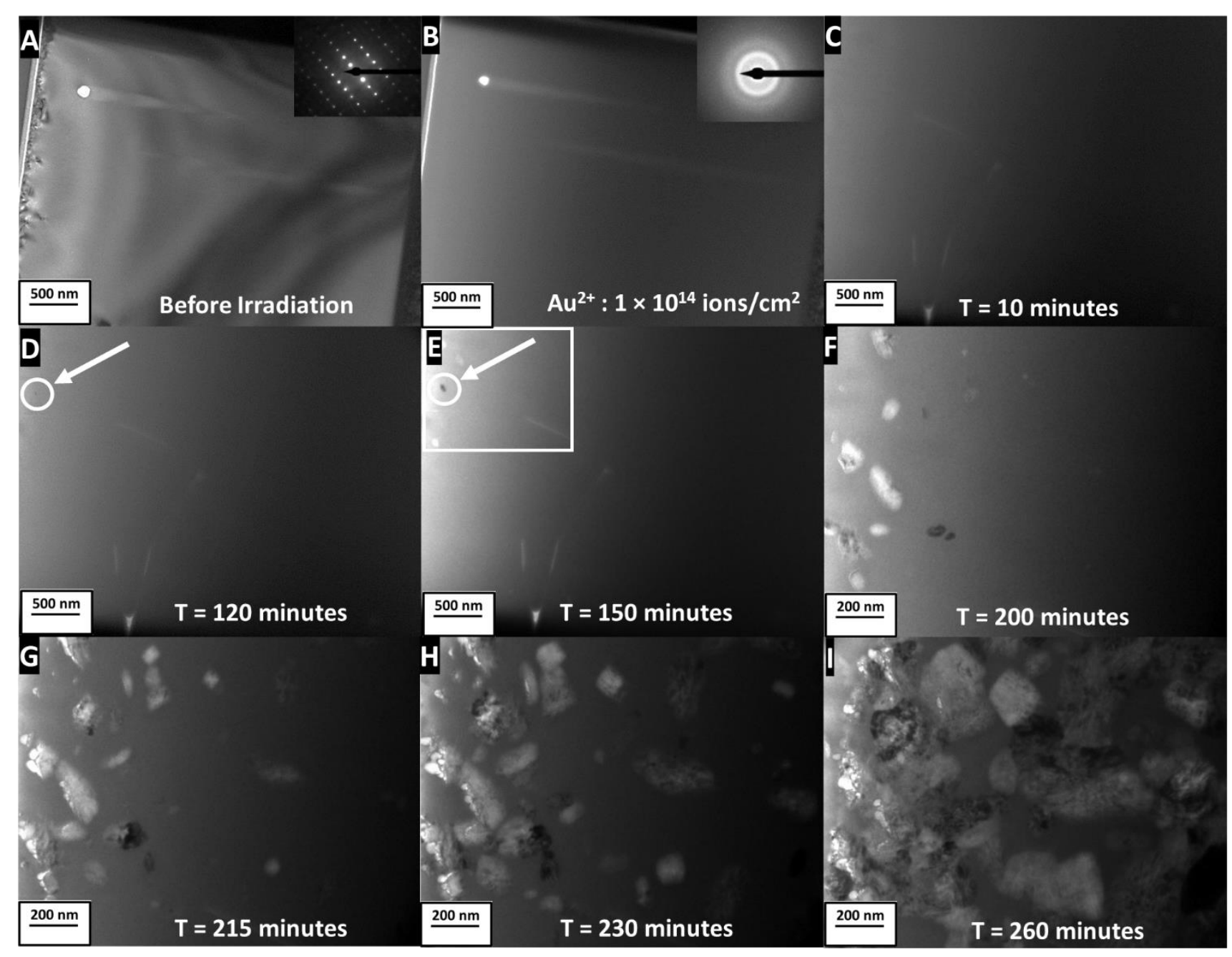


Figure 10

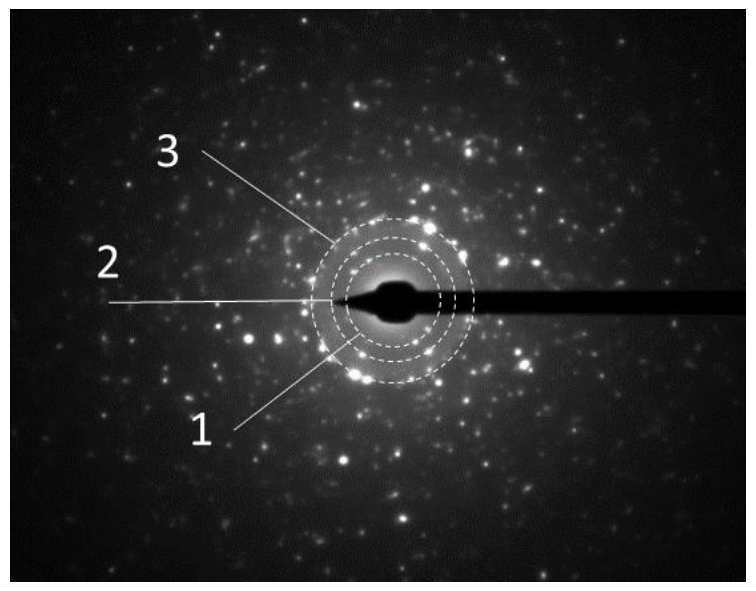


Figure 11

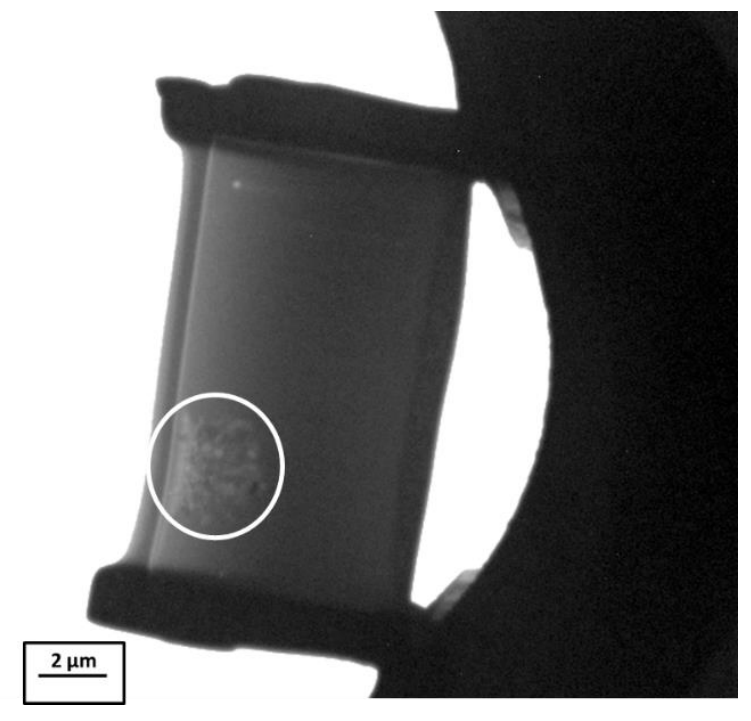


Figure 12

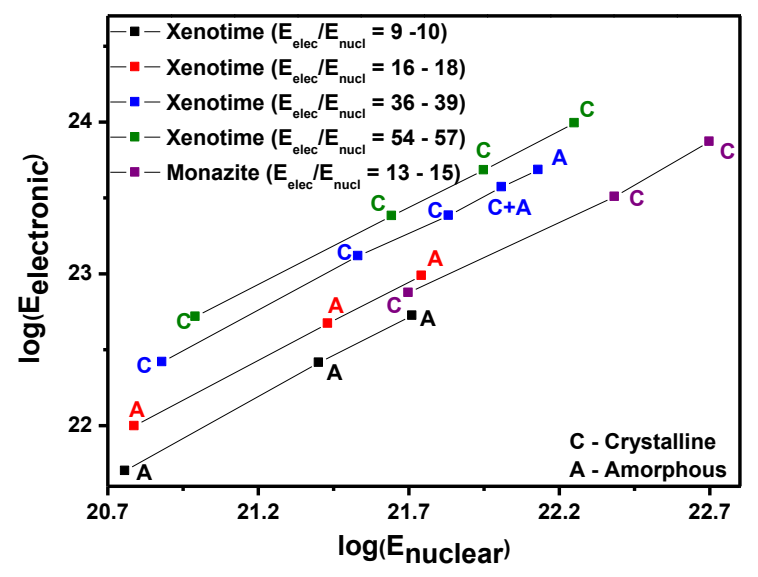

